\title{
CRÓNICA DE JURISPRUDENCIAL LABORAL INTERNACIONAL 2019
}

\section{CHRONICLE OF INTERNATIONAL LABOR JURISPRUDENCE 2019}

\author{
Ángel Arias Domínguez \\ Catedrático de Derecho del Trabajo y de la Seguridad Social \\ Universidad de Extremadura
}

Recibido: 08.06.2020 / Aceptado: 15.06.2020

DOI: https://doi.org/10.20318/cdt.2020.5638

Resumen: En el período de referencia no se han dictado resoluciones relevantes del Comité de Libertad Sindical, ni tampoco se ha pronunciado el TEDH en asuntos que afecten al estado español. Sin embargo sí contamos con numerosas resoluciones del TJUE que afectan al estado Español que pasamos a exponer, junto con tres resoluciones del Tribunal afectantes a otros ordenamientos que por su interés también reseñamos.

La STJUE de 22 de enero de 2019 [C-193/17] Cresco Investigation GmbH y M.A. aborda un problema de discriminación religiosa porque el ordenamiento jurídico concede un día adicional de descanso laboral a los miembros de determinadas confesiones religiosas. Aun no afectando al ordenamiento jurídico español se ha considerado interesante comentarla.

El ATJUE de 19 de marzo de 2019 [C-293/18] CCOO de Galicia y Universidad de Santiago de Compostela, cuestiona la adecuación a la legalidad comunitaria de una norma nacional que no prevé indemnización por finalización de contrato de trabajo en modalidades de contratación predoctoral para tareas de investigación.

En la STJUE de 26 de marzo [C-377/16] Reino de España c. Parlamento Europeo, se debate la legalidad de una oferta de empleo del Parlamento que exige que los candidatos conozcan como segunda lengua exclusivamente el alemán, el inglés o el francés.

La STJUE de 11 de abril de 2019 [C-29/18, C-30/18 y C-44/18] Cobra Servicios c. J. D. Sánchezy otros, aborda un tema muy conocido, la diferente indemnización que proceden por la extinción de contratos de trabajo de diferente naturaleza, por finalización de una contrata para los de obra o servicio vinculados, y por causa económica para los de naturaleza fija.

La STJUE de 8 de mayo de 2019 [C-161/18] Villar Láiz c. INSS y TGSS, trata sobre la discriminación indirecta por razón de sexo que provoca la norma que regula el cálculo de la pensión a tiempo parcial.

La muy interesante, aunque poco efectiva dada la modificación legislativa operada entre el planteamiento de la cuestión y su resolución, STJUE de 14 de mayo de 2020 [C-55/18] Federación de Servicios CC.OO. c. Deutsche Bank aborda una cuestión comprometida, el control de la jornada laboral empleando para ello un mecanismo ideado únicamente para el control de las horas extraordinarias.

El ATJUE de 12 de junio de 2019 [C-367/18] María Teresa Aragón Carrasco y otros c. Administración del Estado entiende que no contradice el ordenamiento comunitario la norma interno que no patrocina indemnización alguna por la extinción de contratos eventuales de confianza.

La STJUE de 20 de junio de 2019 [C-72/18] Daniel Ustariz Aróstegui c. Dto. Educación Gobierno de Navarra aprecia que es contrario a la normativa comunitaria el establecimiento de un complemento económico vinculado a la condición del funcionario en el sector de la enseñanza. 
La tutela antidiscriminatoria por embarazo no es patrimonio del ordenamiento patrio. Tiene una nueva versión con la STJUE de 20 de junio de 2019 [C-404/18] Jamina Hakelbracht y Tine Vandenbon c. WTG Retail BVBA, en la que se otorga la tutela normativa a un testigo no formal del proceso de no contratación de una trabajador por estar embarazada.

Aunque ha perdido actualidad por la supresión en nuestro ordenamiento jurídico del despido objetivo por absentismo la STJUE de 11 de septiembre de 2019 [C-397/8] DW c. Nobel Plastiques Ibérica analiza si las ausencias al trabajo por enfermedad relacionada con la discapacidad que padece el trabajador pueden considerarse computables a efectos del despido objetivo por absentismo.

En la STJUE de 18 de septiembre de 2019 [C-366/18] Ortiz Mesonero c. UTE Luz Madrid, se discutía si el trabajador que trabaja en una empresa a turnos puede elegir la adscripción al turno de mañana con el objeto de favorecer la conciliación de la vida familiar y laboral.

El ATJUE de 15 de octubre de 2019 [C-439/18 y C-472/18] $O H$ y ER c. $A E A T$ entiende irrazonable la exclusión de los períodos no trabajados por los trabajadores fijos-discontinuos del cómputo de la antigüedad a efectos del percibo de complementos retributivos.

La interesante STJUE de 7 de noviembre de 2019 [C-396/18] Gennaro Cafaro c. $D Q$ estudia un tema siempre interesante como lo es la discriminación laboral por motivos de edad, y aunque no afecta al ordenamiento español se ha considero oportuno tratarla.

La STJUE de 5 de diciembre de 2019 [C-398/18 y C-428/18] Bocero Torrico y Fritz Bode c. INSS y TGSS trata sobre la cuantía mínima de la jubilación anticipada, entendiendo que las normas de la Unión se opone a que para concederla se exija que su cuantía tenga que se superior a la que recibiría cuando cumpliese la edad ordinaria de jubilación.

La última sentencia comentada de este año es la STJUE de 12 de diciembre de 2019 [C450/18] WA c. INSS que entiende que el complemento de maternidad que idea la LGSS para complementar las prestaciones de las mujeres que han sido madres debe interpretarse en el sentido de no excluir de su percibo a los varones que se encuentre en idéntica situación.

Palabras clave: Discriminación laboral por motivos religiosos,indemnización por finalización de contrato predoctoral para tareas de investigación,discriminación por motivos lingüísticos en una contratación por la Unión Euro-pea,diferente indemnización por finalización de los contratos por obra o servicio vinculada a contrata versus fijos por causa económica,control de la jornada de trabajo, horas extraordinarias,no indemnización por extinción de contrato eventual de confianza, complemente económico sólo perceptible por funciona-rios, tutela antidiscriminatoria en supuestos de embarazo, despido objetivo por absentismo y enfermedad, conciliación de la vida familiar y adscripción a un concreto turno de trabajo, trabajadores fijos-discontinuos y complementos de antigüedad, discriminación laboral por motivos de edad, cuantía míni-ma de la pensión de jubilación anticipada,complemento de maternidad y discriminación a los varones que se encuentren en idéntica situación.

Abstract: During the reference period, no relevant resolutions of the Committee on Freedom of Association have been issued, nor has the ECtHR ruled on matters affecting the Spanish state. However, we do have numerous resolutions of the CJEU that affect the Spanish state that we are going to present, along with three resolutions of the Court that affect other legal systems that we also reviewed for your interest.

The STJUE of January 22, 2019 [C-193/17] Cresco Investigation GmbH and M.A., addresses a problem of religious discrimination because the legal system grants an additional day off from work to members of certain religious denominations. Even without affecting the Spanish legal system, it has been considered interesting to comment on it.

The ATJUE of March 19, 2019 [C-293/18] CCOO of Galicia and the University of Santiago de Compostela, questions the adequacy of a national law that does not provide for compensation for termination of employment contract in terms of employment predoctoral for research tasks.

In the STJUE of March 26 [C-377/16] Kingdom of Spain c. European Parliament, the legality of a job offer from Parliament is being debated, which requires that candidates only know German, English or French as a second language.

The STJUE of April 11, 2019 [C-29/18, C-30/18 and C-44/18] Cobra Servicios c. J. D. Sánchez and others, deals with a well-known topic, the different compensation that comes from the termi- 
nation of employment contracts of different nature, for the termination of a contract for those of related work or service, and for economic reasons for those of a fixed nature.

The STJUE of May 8, 2019 [C-161/18] Villar Láiz c. INSS and TGSS, deals with indirect discrimination based on sex caused by the norm that regulates the calculation of the part-time pension.

The very interesting, although ineffective given the legislative amendment made between the approach to the issue and its resolution, STJUE of May 14, 2020 [C-55/18] Federation of Services CC.OO. c. Deutsche Bank addresses a compromised issue, the control of working hours using a mechanism designed solely for the control of overtime.

The ATJUE of June 12, 2019 [C-367/18] María Teresa Aragón Carrasco and others c. The State Administration understands that the community law does not contradict the internal norm that does not sponsor any compensation for the termination of possible trust contracts.

The STJUE of June 20, 2019 [C-72/18] Daniel Ustariz Aróstegui c. disc. Education The Government of Navarra appreciates that the establishment of an economic supplement linked to the status of civil servant in the education sector is contrary to Community regulations.

Anti-discrimination guardianship for pregnancy is not the patrimony of the national order. It has a new version with the STJUE of June 20, 2019 [C-404/18] Jamina Hakelbracht and Tine Vandenbon c. WTG Retail $\boldsymbol{B V B} \boldsymbol{A}$, in which the normative guardianship is granted to an informal witness of the process of not hiring a worker for being pregnant.

Although the STJUE of September 11, 2019 [C-397/8] DW c. Nobel Plastiques Ibérica its relevance due to the suppression in our legal system of the objective dismissal for absenteeism. Nobel Plastiques Ibérica analyzes whether absences from work due to illness related to the disability suffered by the worker can be considered computable for the purposes of objective dismissal due to absenteeism.

In the STJUE of September 18, 2019 [C-366/18] Ortiz Mesonero c. UTE Luz Madrid, it was discussed whether the worker who works in a shift company can choose to join the morning shift in order to favor the reconciliation of family and work life.

The ATJUE of October 15, 2019 [C-439/18 and C-472/18] $O H$ and ER c. $A E A T$ considers unreasonable the exclusion of periods not worked by permanent-discontinuous workers from the calculation of seniority for the purposes of receiving remuneration supplements.

The interesting STJUE of November 7, 2019 [C-396/18] Gennaro Cafaro c. $D Q$ studies an always interesting topic such as employment discrimination on the grounds of age, and although it does not affect the Spanish law, it has been considered appropriate to deal with it.

The STJUE of December 5, 2019 [C-398/18 and C-428/18] Bocero Torrico and Fritz Bode c. INSS and TGSS deals with the minimum amount of early retirement, understanding that the Union regulations preclude the granting of this requirement that its amount must be higher than what it would receive when it reached the ordinary retirement age.

The last annotated sentence of this year is the STJUE of December 12, 2019 [C-450/18] WA c. INSS that understands that the maternity supplement devised by the LGSS to complement the benefits of women who have been mothers must be interpreted in the sense of not excluding from their receipt men who are in the same situation.

Keywords: Labor discrimination on religious grounds, compensation for completion of predoctoral contract for re-search tasks, discrimination on linguistic grounds in recruitment by the European Union, different com-pensation for termination of contracts for work or service linked to contracts versus fixed for economic reasons, control of the working day, extraordinary hours, no compensation for termination of eventual trust contract, completely economic only perceivable by officials, anti-discrimination guardianship in cases of pregnancy, objective dismissal for absenteeism and illness, reconciliation of family life and as-signment to a specific work shift,fixed-discontinuous workers and seniority accessories, employment dis-crimination on the grounds of age, minimum amount of the early retirement pension, maternity supple-ment and discrimination against men who are in the same situation.

Sumario: I. TRIBUNAL DE JUSTICIA DE LA UNIÓN EUROPEA.1. STJUE de 22 de enero de 2019 [C-193/17]. Cresco Investigation GmbH y M.A. Discriminación directa por motivos 
religiosos al conceder días de permiso laboral retribuido únicamente a miembros de determinadas confesiones religiosas.2. ATJUE de 19 de marzo de 2019 [C-293/18] CC.OO. de Galicia y Universidad de Santiago de Compostela. Pretendida discriminación en contratos predoctorales de investigación que no prevén indemnización a su término.3. STJUE de 26 de marzo de 2019 [C-377/16] Reino de España c. Parlamento Europeo. Oferta de empleo del Parlamento Europeo y conocimiento de dos lenguas de la Unión por los candidatos.4. STJUE de 11 de abril de 2019 [C-29/18, C-30/18 y C-44/18] Cobra Servicios c. J. D. Sánchez y otros. Diferente indemnización por finalización de contrata que por extinción objetiva por causa económica.5. STJUE de 8 de mayo de 2019 [C-161/18] Villar Láiz c. INSS y TGSS. Discriminación indirecta por razón de sexo en el cálculo de la pensión de jubilación a tiempo parcial.6. STJUE de 14 de mayo de 2020 [C-55/18] Federación de Servicios CC.OO. c. Deutsche Bank. Control de la jornada diaria de trabajo, no sólo de las horas extraordinarias.7. ATJUE de 12 de junio de 2019 [C-367/18] María Teresa Aragón Carrasco y otros c. Administración del Estado. No indemnización por extinción de contratos eventuales de confianza.8. STJUE de 20 de junio de 2019 [C-72/18] Daniel Ustariz Aróstegui c. Dto. Educación Gobierno de Navarra. La percepción de un complemento retributivo en el sector de la enseñanza sólo por funcionarios es contrario a la normativa comunitaria.9. STJUE de 20 de junio de 2019 [C-404/18] Jamina Hakelbracht y Tine Vandenbon c. WTG Retail BVBA. Tutela antidiscriminatoria refleja por embarazo a testigos del proceso de contratación.10. STJUE de 11 de septiembre de 2019 [C-397/8] $D W$ c. Nobel Plastiques Ibérica. Absentismo por motivos de discapacidad y despido por faltas de asistencia al trabajo.11. STJUE de 18 de septiembre de 2019 [C-366/18] Ortiz Mesonero c. UTE Luz Madrid. Adscripción a turno de trabajo para la conciliación de la vida familiar y laboral.12. 12. ATJUE de 15 de octubre de 2019 [C-439/18 y C-472/18] OH y ER c. AEAT. Devengo de trienios de fijos-discontinuos.13. STJUE de 7 de noviembre de 2019 [C-396/18] Gennaro Cafaro c. DQ. Discriminación laboral por motivos de edad.14. STJUE de 5 de diciembre de 2019 [C-398/18 y C-428/18] Bocero Torrico y Fritz Bode c. INSS y TGSS. Pensión de jubilación anticipada y cuantía mínima.15. STJUE de 12 de diciembre de 2019 [C-450/18] WA c. INSS. El complemento de maternidad no debe excluir de su percibo a los varones que se encuentre en idéntica situación.

\section{Tribunal de justicia de la Unión Europea}

1. La jurisprudencial analizada en esta crónica de resoluciones del TJUE en las que España ha sido parte, o que tengan especial relevancia para al ámbito social del derecho, ha sido extraída de la base de datos oficial del Tribunal (InfoCuria) en atención a los siguientes tesauros conceptuales: Derechos fundamentales; Empleo; Libre circulación de los trabajadores; No discriminación, Politica social, y Seguridad Social.

Se reseñan todos los asuntos que afectan directamente a España en el período temporal referenciado, y también dos resoluciones sobre ética religiosa en el trabajo y sobre la traducción del disfrute de vacaciones en indemnización económica en caso de fallecimiento sin haberlas disfrutado en su debido tiempo que, aunque no afecten a España son interesantes desde el punto de vista laboral.

\section{STJUE de 22 de enero de 2019 [C-193/17] Cresco Investigation GmbH y M.A. Discriminación directa por motivos religiosos al conceder días de permiso laboral retribuido únicamente a miem- bros de determinadas confesiones religiosas}

\section{A) Hechos del litigio principal}

2. El derecho laboral Austríaco prevé, al margen de la normativa laboral general aplicable a todos los trabajadores, la concesión de un día adicional de descanso laboral en Viernes Santo, con carácter remunerado, pero exclusivamente para cuatro confesiones religiosas: los miembros de las Iglesias Evangélicas de la confesión de Augsburgo, de la confesión Helvética, y de la confesión metodista, y a los miembros de la Iglesia Católica Antigua. 
El señor A es un trabajador por cuenta ajena, pero no pertenece a ninguna de las referidas iglesias. Solicitó el abono del día concreto pero no se le concedió por la empresa, considerando, en definitiva, que la decisión empresarial es discriminatoria

Después de varias vicisitudes llega el asunto a la instancia superior que precisa dos cuestiones con carácter previo al planteamiento de la cuestión prejudicial: que los días festivos en la normativa austríaca son considerados como laborales y retribuidos, y que los días adicionales discutidos se incorporan en una norma singular para favorecer la práctica de la religión en los concretos días discutidos.

\section{B) Cuestión jurídica debatida}

3. Pero el Tribunal no tiene claro si la concesión de ese día adicional únicamente a los trabajadores de una concreta religión puede considerarse acorde al derecho de la Unión Europea, pudiendo apreciarse como un tratamiento discriminatorio en contra de los trabajadores que no profesan esa fe, pues las personas que no pertenecen a esas confesiones religiosas disfrutan a lo largo del año de un día remunerado menos que los que sí pertenecen a estas confesiones.

La cuestión prejudicial se circunscribe a determinar, por tanto, si se opone al ordenamiento de la Unión Europea una regla técnica laboral que entiende que el Viernes Santo únicamente se considera festivo para trabajadores que profesen una determinada religión, y que el trabajador de las mismas que efectivamente trabaje ese día tiene derecho a una retribución adicional por el trabajo realizado, además de la que le corresponde por el día festivo no trabajador, mientras que dicho abono no le percibe el trabajador que no pertenezca a esas confesiones.

De manera complementaria se pregunta, únicamente para el supuesto de que efectivamente se haya considerado que la medida es discriminatoria, si hasta que la legislación austríaca se modifique los empleadores privados se encuentra obligados a conceder a los trabajadores que no profesen esas religiones el derecho al día festivo por Viernes Santo, y a abonar, en el caso de que trabajen ese concreto día, la remuneración correspondiente.

Se está cuestionando, en definitiva, si estamos en presencia de una discriminación directa por motivos religiosos.

\section{C) Normativa UE en presencia}

4. Directiva 2000/78/CE del Consejo, de 27 de noviembre de 2000, relativa al establecimiento de un marco general para la igualdad de trato en el empleo y la ocupación.

\section{D) Resolución del Tribunal}

5. El TJUE no duda, ni por un momento, que efectivamente la norma cuestionada trata de diferente manera a los trabajadores por motivos religiosos ( $(50)$, ni tampoco de que la concesión de ese día adicional de descanso y el abono salarial del día en caso de que efectivamente trabaje un miembro de esas confesiones persigue una finalidad amparable bajo la óptica del derecho nacional (§ 57), legítima por tanto bajo el prisma de la Unión Europea.

Queda por apreciar si la norma laboral interna que privilegia a los trabajadores de determinadas confesiones religiosa es necesaria para el fin pretendido ( $(59)$, porque, se recuerda por el Tribunal, el derecho de la Unión ampara normativas internas a priori discriminatorias destinadas a suprimir o minimizar las desigualdades fácticas que eventualmente pudieran existir en la realidad social (§ 64) por lo que el análisis de la utilidad de la norma en su contexto se revela como elemento fundamental de su legalidad comunitaria, teniendo en consideración, naturalmente, el principio de proporcionalidad que patrocina que el régimen de excepción a la norma general sea objetivo, razonable y se establezca para la tutela de un fin legítimo $(\S 65)$. 
El Tribunal entiende que la normativa cuestionada establece "una diferencia de trato entre trabajadores sometidos a obligaciones religiosas análogas" (§ 68), diferencia de trabajo que no es acorde al principio de igualdad comunitario.

En definitiva, el Tribunal entiende discriminatoria la normativa nacional que por motivos religiosos concede un día de descanso retribuido en Viernes Santos únicamente a los trabajadores que profesen unas determinadas religiones, abonándose dicho día de manera adicional si efectivamente deben trabajar ese concreto día, no entendiendo que estemos en presencia de una norma necesaria para la protección específica de los derechos en presencia (\$ 69).

Aunque es una cuestión colateral, y de muy limitada trascendencia, conviene precisar que el Tribunal entiende que efectivamente los empleadores privados hasta que se modifique la norma nacional interna sí tienen la obligación de conceder a todos los trabajadores el derecho al día festivo de Viernes Santo, siempre que lo hayan solicitado, y a abonar el complemento por trabajo realizado en el supuesto de que efectivamente trabajasen $(\S \S 70$ y 89$)$.

\section{E) Apunte final}

6. La resolución objeto de comentario se trae a esta tribuna por dos motivos. En primer lugar, porque no son frecuentes en el ámbito Europeo las discriminaciones por motivos religiosos, y, en segundo, lugar porque aunque no es una cuestión especialmente problemática en España los planes gubernamentales de modificar el Estatuto de los Trabajadores para introducir festividades religiosas en él pueden poner en breve sobre la mesa el status quo actualmente existente ${ }^{1}$.

Recuérdese que esta cuestión hoy en día se regula en los respectivos arts. 12 de la Ley 25/1992, de 10 de noviembre, por la que se aprueba el Acuerdo de Cooperación del Estado con la Federación de Comunidades Israelitas de España, y de la Ley 26/1992, de 10 de noviembre, por la que se aprueba el Acuerdo de Cooperación del Estado con la Comisión Islámica de España. En ambos preceptos se dispone: "Las festividades que a continuación se expresan, que según" la Ley y la tradición judías / Ley Islámica "tienen el carácter de religiosas, podrán sustituir a las establecidas con carácter general por el Estatuto de los Trabajadores, en su artículo 37.2, con el mismo carácter de retribuidas y no recuperables, a petición de las personas a que se refiere el número anterior, y en los términos previstos en el mismo".

\section{ATJUE de 19 de marzo de 2019 [C-293/18] CC.OO. de Galicia y Universidad de Santiago de Compostela. Pretendida discriminación en contratos predoctorales de investigación que no prevén indemnización a su término.}

\section{A) Hechos del litigio principal}

7. La Universidad pública referenciada formaliza varios "contratos predoctorales" con investigadores en el marco de un proyecto concreto para realizar, específicamente, tareas de investigación. El sindicato referenciado intima una demanda colectiva contra la Universidad solicitando el resarcimiento económico derivado de la finalización del contrato prevista en la normativa laboral común, al entender que existe una diferencia de trato con los trabajadores del régimen laboral común.

La Universidad solicitad, por su parte, la desestimación de la demanda, apoyándose en dos argumentos: que los trabajadores contratados en formación son estructuralmente empleados de duración determinada, que si situación no es comparable con los trabajadores indefinidos, y que estos trabajadores sí tiene derecho a la indemnización en supuestos de despido disciplinario improcedente y de extinción objetiva por causa económica.

\footnotetext{
${ }^{1}$ Así, al parecer, se ha descartado meter "en el calendario laboral de 2020 el final de Ramadán”. Véase la noticia, entre otros periódicos que se hacen eco de ella, en: https://elfarodeceuta.es/gobierno-no-mete-calendario-laboral-2020-final-ramadan/
} 
El Tribunal interno competente suspende el procedimiento y plantea la ahora resuleta cuestión prejudicial.

La resolución da respuesta, en definitiva, a la cuestión prejudicial que le plantea el Tribunal nacional en la que se planteaba el derecho del personal investigador predoctoral en formación contratado por una Universidad pública a percibir una indemnización por finalización de contrato.

\section{B) Cuestión jurídica debatida}

8. La normativa específica que rige esta modalidad de contratación no prevé expresamente una indemnización por su terminación. La norma laboral común, el ET, mantiene como principio técnico de proyección hacia todas las modalidades contractuales de duración temporal o determinada: tendrán los mismos derechos que los contratos de duración indefinida, permitiéndose, no obstante, singularidades específicas en materia de extinción en relación con los contratos de carácter formativo.

El Tribunal proponente de la cuestión aprecia que el caso difiere del que dio lugar a la sentencia de 14 de septiembre de 2016 [C596/14] De Diego Porras (EU:C:2016:683), básicamente porque la duración del contrato se establece objetivamente en la norma que disciplina el régimen jurídico de la contratación, considerándolo claramente de carácter temporal, sin que se prevea indemnización por su finalización $(\S 21)$.

El Tribunal nacional pregunta, básicamente, si este tipo de trabajadores se encuentran incluidos en la Directiva 1999/70/CE y si le es aplicable la indemnización por finalización de contrato, para lo cual formula cuatro cuestiones concretas $(\S 23)$.

\section{C) Normativa UE en presencia}

9. Directiva 1999/70/CE del Consejo, de 28 de junio de 1999, relativa al Acuerdo Marco de la CES, la UNICE y el CEEP sobre el trabajo de duración determinada.

La noma jurídica interna controvertida es la Ley 14/2011, de 1 de junio, de la Ciencia, la Tecnología y la Innovación, especialmente el art. 21 que regula el régimen jurídico del "contrato predoctoral".

\section{D) Resolución del Tribunal}

10. No tiene dudas el Tribunal en entender que estos trabajadores sí se encuentran incluidos en el ámbito de aplicación de la Directiva referenciada (§ 34). Aprecia que tanto de los dictados normativos de la misma (§ 29) como de la jurisprudencia evacuada sobre su interpretación $(\S 28)$ no puede deducirse otra conclusión, pues la Directiva no excluye a ningún sector de actividad (§ 30$)$.

El problema jurídico, por tanto, no pivota sobre es si la norma comunitaria es o no aplicable, que lo es, sino sobre si puede apreciar una diferencia de trato en el momento de la extinción del contrato en relación con los trabajadores indefinidos.

El Tribunal recuerda que uno de los principios clave en la materia es el de no discriminación de los trabajadores con duración determinada $(\S 38)$, no consistiendo tratos diferenciales que no se encuentren "objetivamente justificados" (§ 42).

Para la resolución del asunto se centra, básicamente, en apreciar si los trabajadores controvertidos desempeñaban las mismas funciones que los trabajadores contratados indefinidos por el mismo empresario (§ 45). El Tribunal proponente de la cuestión entiende que, efectivamente, los trabajadores contratados para la modalidad predoctoral se encuentran en una situación comparable a los contratados por tiempo indefinido, por lo que el debate se desplaza hacia la consideración justificada o no de la diferencia de trato en relación con la extinción por fin de contrato ( $(46)$, basada en "elementos precisos y concretos" que verifiquen que "dicha desigualdad responde a una necesidad auténtica" (§ 47). 
El Tribunal de justicia entiende que la finalización de un contrato por el vencimiento del término se produce en un "contexto sensiblemente diferente, desde los puntos de vista fáctico y jurídico" que el de un trabajador fijo cuyo contrato finaliza por el advenimiento de las causas objetivamente previstas en la normativa nacional $(\S 48)$.

En la contratación controvertida estamos en presencia de un tipo de contrato temporal en el que las partes contratantes "conocen, desde el momento de su celebración, la fecha o el hecho que determina su término" (§ 49), circunstancia determinante del diferente régimen jurídico en relación a los contratos indefinidos, pues en estos últimos la indemnización por finalización pretende "compensar el carácter imprevisto de la ruptura de la relación de trabajo" (\$ $\mathbf{5 0 )}$.

El Tribunal de Justicia entiende, en definitiva, que la Directiva invocada no se opone a la regulación de unos contratos como estos predoctorales que no prevén indemnización alguna por la llegada del término final previsto en la propia normativa (§ 53), aunque sí se conceda dicha indemnización a los trabajadores indefinidos.

\section{E) Apunte final}

11. Una resolución más, de las muchas ya dictadas, sobre indemnización en supuestos de contratación temporal. En este caso en relación a algunas de las modalidades de contratación que se emplean por las Universidad Públicas.

Siendo razonable la solución a la que llega el Tribunal de Justicia, se echa de menos una argumentación más potente sobre la naturaleza temporal de la actividad de investigación que se desarrolla bajo la modalidad "predoctoral" cuestionada. El Tribunal escora esta cuestión, centrándose en la eficacia de la condición resolutoria, con lo que deja imprejuzgada la cuestión desde el punto de vista sustancial, porque lo mollar, lo verdaderamente trascendente en cuestionar si la actividad desarrollada se adecua al carácter temporal del contrato signado. El planteamiento de la cuestión determinan, qué duda cabe, los límites de discusión y resolución del Tribunal que, entendemos, debería haber sido configurados para dar cabida a esta aspecto no tratado.

\section{STJUE de 26 de marzo de 2019 [C-377/16] Reino de España c. Parlamento Europeo. Oferta de empleo del Parlamento Europeo y conocimiento de dos lenguas de la Unión por los candidatos}

\section{A) Hechos del litigio principal}

12. El reino de España impugna ante el Tribunal de Justicia una convocatoria del Parlamento Europeo de "manifestaciones de interés" para confeccionar una base de datos de candidatos para ser contratados como "agentes contractuales para el ejercicio de la función de conductores" (§ 18). Los puestos de trabajo ofertados son, aproximadamente, ciento diez teniendo como lugar de trabajo Bruselas.

En la convocatoria se especifica, en el apartado relativo a las "Condiciones de admisión", entras otras exigencias, que los candidatos debe conocer dos lenguas oficiales de la Unión. De una de las veinticuatro lenguas oficiales debe poseer un "profundo conocimiento". De la segunda lengua debe tener un "conocimiento satisfactorio". Pero esa segunda lengua, de manera obligatoria, tiene que ser una de las siguientes: alemán, inglés o francés (§ 20).

Se justifica la restricción con respecto a la segunda lengua, en el sentido de que necesariamente tengan que ser alguna de las tres mencionadas por razones de funcionalidad operativa, de práctica y realización inmediata de las tareas laborales encomendadas (§22).

La particularidad del caso, que se aprecia más fácilmente en la lectura de la fundamentos jurídicos que en la exposición de los hechos, es que el formulario que obligatoriamente deben los candidatos rellenar, siempre on line, sólo puede protocolizarse empleando algunas de las tres lenguas referidas (alemán, inglés o francés), estando cuestionado este punto porque el propio formulario no indica que puede "cumplimentarse en cualquier lengua oficial de la Unión" y porque precisamente por eso los candidatos 
podrían razonablemente presumir "que debía cumplimentarse obligatoriamente en una de aquellas tres lenguas" (§ 44).

\section{B) Cuestión jurídica debatida}

13. El Reino de España solicita la anulación de la convocatoria por cuatro motivos. En primer lugar, porque considera ilegal la restricción que se realiza en la convocatoria en relación a las lenguas que deben emplearse en el procedimiento de comunicación entre el órgano seleccionador de personal y los candidatos. La convocatoria exige que dicha comunicación se efectúe exclusivamente en alguna de estas tres lenguas: inglés, francés o alemán (§ 30).

En segundo lugar, entiende incorrecta la exigencia lingüística de la convocatoria de conocer una segunda lengua en relación con las funciones que tienen que desempeñar los futuros trabajadores (\$ 31).

En tercer y cuarto lugar entiende que la limitación a las tres lenguas referidas en la acreditación del "conocimiento suficiente" de la segunda lengua es ilegal (§ 32)

\section{C) Normativa UE en presencia}

14. Reglamento núm. 1 del Consejo, de 15 de abril de 1958, por el que se fija el régimen lingüístico de la Comunidad Económica Europea, en su versión modificada por el Reglamento núm. 517/2013 del Consejo, de 13 de mayo de 2013.

Reglamento núm. 259/68 del Consejo, de 29 de febrero de 1968, por el que se establece el Estatuto de los Funcionarios de las Comunidades Europeas y el Régimen aplicable a los otros agentes de estas Comunidades y por el que se establecen medidas específicas aplicables temporalmente a los funcionarios de la Comisión, en su versión modificada por el Reglamento núm. 1023/2013 del Parlamento Europeo y del Consejo, de 22 de octubre de 2013.

\section{D) Resolución del Tribunal}

15. Con respecto a la primera alegación del Reino de España, la relativa a que los candidatos debe poder presentar la solicitud y mantener comunicación con la oficia de selección de personal en la lengua oficial de la Unión que de desee ( $§ 33$ y 34).

El Tribunal entiende, después de reconocer el derecho a la diversidad lingüística (§36) y que ese principio no puede llevarse al extremo de consentir que se permita elegir cualquier lengua para la redacción de cualquier tipo de comunicación, pues existen excepciones razonables según las circunstanciad de cada caso ( $(37)$, que el hecho de que 'pareciera' que el formulario sólo podía rellenarse en alguna de las tres lenguas referenciadas puede razonablemente entenderse lesivo de sus intereses (§ 46). En definitiva que la indisponibilidad del formulario para la convocatoria en todos los idiomas puede considerarse que somete a los candidatos cuya lengua preferida sea distinta a algunas de las tres referenciadas es someter a dichos candidatos a "un trato menos favorable que el reservado a los candidatos cuya lengua oficial preferida correspondía a una de esas tres" (§ 47).

Se estima, en definitiva, el primer motivo de impugnación (§ 52).

La segunda alegación cuestiona que sea exigible que estos trabajadores concretos deben conocer una segunda lengua pues "no resulta necesario para el ejercicio de las funciones que los candidatos seleccionados tienen que desempeñar" (§53). El Tribunal desestima dicha alegación, entendiendo que el Reglamento del Estatuto de los Funcionarios exige el conocimiento de una segunda lengua ( $\$ 59)$.

La tercera y cuarta alegación cuestionan la restricción de conocimiento de la segunda lengua a las tres referenciadas, pues dicha limitación -a juicio del Reino de España- no protege un "objetivo legitimo de interés general", no siendo una restricción profesional (§ 61).

El Tribunal entiende, sin demasiada argumentación artificiosa, que esta limitación "constituye una diferencia de trato por razón de la lengua" (§ 66). 
Se trata ahora de apreciar si dicha restricción responde a un "interés legitimo" (§ 67) en el sentido de acreditar que dicha "limitación es efectivamente apta para responder a necesidades reales $y$ efectivas" (\$ 69).

El Tribunal entiende que la convocatoria de la oferta de empleo "no aborda en modo alguno la justificación de esta limitación con respecto a las necesidades lingüisticas concretas relativas a las funciones que los conductores contratados tendrán que desempeñar" (§ 74).

Estimadas las cuestiones principales la convocatoria debe anularse, como también la base de datos formalizada con las solicitudes efectuadas ( $\S \S 80$ y 88$)$.

\section{E) Apunte final}

16. La resolución plantea un tema que no está siempre bien resuelto en un ordenamiento jurídico como el nuestro que cuenta con varias lenguas cooficiales en determinadas Comunidades Autónomas, y que es común que se incorpore, en las ofertas de empleo público de las Comunidades Autónomas, la exigencia de conocer varias lenguas cooficiales, con un claro propósito discriminatorio contra los ciudadanos que sólo conocer la lengua mayoritaria usada en el país.

Pues bien, en atención a los criterios que se deducen de esta resolución, que ha sido reiterada por la STJUE de 8 de mayo de 2020 [C-243/18 P] Empresa Común Europea c. Yosu Galocha, la exigencia de conocer varios idiomas, mutatis mutandis varias lenguas cooficiales, debe venir justificada en razones que se relacionen con el servicio que se va a prestar una vez contratado y la necesidad de prestarlo, precisamente, en la lengua cooficial, pudiendo deducirse, en caso contrario, un trato discriminatorio.

\section{STJUE de 11 de abril de 2019 [C-29/18, C-30/18 y C-44/18] Cobra Servicios c. J. D. Sánchez y otros. Diferente indemnización por finalización de contrata que por extinción objetiva por causa económica}

\section{A) Hechos del litigio principal}

17. Las cuestiones prejudiciales acumuladas se han presentado en el contexto de tres ligios entre la empresa y tres trabajadores y el Fondo de Garantía Salarial.

La empresa demandada firmó en agosto de 2011 una contrata con una gran empresa distribuidoras (no demandada en este procedimiento) de suministros (electricidad y gas) para la prestación del servicio de lectura de contadores en una provincia concreta. En base a esa contrata la empresa Cobra contrató a los trabajadores ahora demandantes.

En febrero de 2015 la empresa suministradora resolvió la contrata con efectos de marzo de ese mismo año. Comunicó seguidamente a los trabajadores que sus contratos de trabajo finalizaban, precisamente por la terminación de la contrata. A todos los trabajadores se les comunicó que recibirían las indemnización económica que procede en el ordenamiento jurídico español por terminación de un contrato de trabajo de carácter temporal (art. 49.1.c) ET).

Seguidamente, y por la misma causa, intimó un expediente de regulación de empleo que afectaba a otros 72 trabajadores con contrato de trabajo indefinido "que efectuaban también tareas en el marco de la ejecución de la contrata" (§ 19).

Esta es la particularidad que acontece en este asunto, que un mismo hecho fáctico con consecuencias jurídicas -la terminación de la contrata- provoca dos tipos de extinciones distintas: la relacionada con los contratos de trabajo por obra o servicio determinados celebrados al ampara de la contrata celebrada con la empresa principal de suministros, y, también apoyándose en esas circunstancias, la extinción mediante un expediente de regulación de empleo por causa económica de los trabajadores fijos de la empresa.

Las acciones judiciales impetradas por los trabajadores devinieron en una sentencia del Juzgado de lo Social competente que entendió que los contratos de trabajo se había realizado en fraude de ley, 
condenando a la empresa Cobra a la readmisión de los trabajadores o al abono de la indemnización por despido disciplinario improcedente (art. 56.1 ET).

La decisión fue recurrida y el Tribunal Superior de Justica competente que entiende que no se encuentra suscrito en fraude de ley el contrato de trabajo por obra o servicio que se suscribe al amparo de una contrata (§24). Entiende, por ello, que el contrato de trabajo se vincula a la existencia de la contrata, que puede ser de duración incierta $(\$ 26)$. Sigue así el camino natural y trillado en nuestro ordenamiento jurídico. Ninguna novedad al respecto.

Entiende el Tribunal, y esta es la singularidad de la resolución, que los trabajadores fijos de la empresa incluidos en ese expediente de regulación de empleo deben ser indemnizados mediante la indemnización que el ordenamiento prevé para el despido objetivo procedente (art. 53.1.b) ET), es decir, 20 días por años de servicio trabajado, mientras que los trabajadores con este contrato de trabajo temporal, es decir, con un contrato de trabajo vinculado a una contrata deben ser indemnizados con la cantidad prevista para la extinción de los contratos por obra o servicio determinado (art. 49.1.c) ET), es decir, con 12 días por años de servicio ( $(28)$, deduciendo de esta diferencia una discriminación en el trato que el ordenamiento dispensa a ambos tipos de trabajadores (§ 29), preguntándose, en definitiva, si existe una justificación, objetiva y razonable, que consienta esa diferencia de trato $(\S 30)$.

\section{B) Cuestión jurídica debatida}

18. El Tribunal nacional pregunta, básicamente, si la normativa de referencia se opone a una norma nacional que prevé para el mismo supuesto de hecho, la finalización de la contrata, diferentes tipos de indemnizaciones según el tipo de contrato que tengan los trabajadores, menores para el de obra y servicio vinculado a la contrata, y mayores para el fijo extinguido en virtud de la operatividad de una causa económica apreciada de manera colectiva (\$ 32).

\section{C) Normativa UE en presencia}

19. Acuerdo Marco sobre el Trabajo de Duración Determinada, celebrado el 18 de marzo de 1999, que figura en el anexo de la Directiva 1999/70/CE del Consejo, de 28 de junio de 1999, relativa al Acuerdo Marco de la CES, la UNICE y el CEEP sobre el Trabajo de Duración Determinada

\section{D) Resolución del Tribunal}

20. El Tribunal de Justicia no entiende peyorativa esta diferente indemnización para diferentes tipos de contratos ( $\$ 56)$, siguiendo la estela de otros pronunciamientos en sentido similar.

Después de recordar el propósito (§ 35) y operatividad (§ 36) del Acuerdo Marco, y su funcionalidad ( $§ 38$ y 39) subraya que lo esencial para determinar si existe discriminación en el trato dispensado a los diferentes tipos de trabajadores es apreciar si el tratamiento jurídico de ambas situaciones se encuentra "objetivamente justificado" ( $(40)$, para lo que tendrá que apreciar que se encuentra en situación comparable (§ 42) en relación con las funciones que desempeñan (§ 43) unos y otros tipos de trabajadores.

Aprecia, sin ningún género de duda, que ambos tipos de trabajadores -por obra o servicio vinculado por una contrata, e indefinidos de la empresa- desarrollan idéntica función laboral (§ 44), por lo que el debate se desplaza hacia la apreciación de si existe una causa objetiva y razonable que justifique la diferencia de trabajo desde el punto de vista indemnizatorio al finalizar ambos tipos de contratos ( $(45)$.

El Gobierno español justifica la diferencia de trato en que con el abono de la indemnización que procede en la finalización del contrato por obra o servicio se indemniza un acontecimiento "que el trabajador podía anticipar cuando se celebró su contrato de trabajo de duración determinada", cual era la finalización de la contrata. Sin embargo la indemnización que procede en la extinción económica pretende "compensar la frustración de las expectativas legítimas de un trabajador relativas a la con- 
tinuidad de la relación laboral" (§ 47). Es el diferente contexto en el que se firman y desenvuelven los contratos de trabajo lo que justifica el diferente trato indemnizatorio.

Ambos tipos de contratos, reconoce el Tribunal de Justicia, se desarrollan "en un contexto sensiblemente distinto" (§ 48), básicamente porque el de duración determinada conocía desde el comienzo de la relación laboral tanto su carácter temporal, como que su finalización se produciría por la terminación de la contrata suscrita entre el empleador contratante y la empresa suministradora de servicios (§ 49), aspectos y circunstancias que desconocía el trabajador fijo de la empresa (§ 50).

El Tribunal, como se ha comentado, reitera que la normativa referenciada no se opone a dicha diferencia indemnizatoria ( $\$ \S 54$ y 56), aunque entiende que corresponde al Tribunal nacional determinar si la finalización de los contratos por obra o servicio terminan por la finalización de la contrata o por la causa económica, porque, y este argumento es esencial a nuestro juicio, la indemnización que procede en la apreciación de una causa económica no diferencia entre el tipo de trabajador, determinado o indefinido (§ 51).

\section{E) Apunte final}

21. Es probable, más antes que después, que el futuro ET prevea idéntica indemnización por finalización del contrato de trabajo, con independencia del tipo de vinculación contractual que una al trabajador con la empresa. Será únicamente su período de permanencia en la misma el que determinar la indemnización por su extinción, por más matices y justificaciones pretendidamente objetivas y razonables que se quieran apreciar, difícilmente encajables en una dinámica normativa que pretende la no discriminación por el tipo de contrato de trabajo que se desarrolle.

En este caso la cuestión se complica sobremanera al convivir los trabajadores fijos de la empresa con contratados al abrigo de una contrata. Sobre este tema recientemente se ha dictado la STS-SOC 783/2018, de 19 de julio de 2018 que modula y matiza las consecuencias de la consideración de trabajador temporal para aquellos trabajadores que permanente vinculados a la empresa por un contrato por obra o servicio al amparo de una contrata por un período de tiempo muy dilatado (14 años) en los que han acaecido diversas vicisitudes de la vida de dicha contrata ${ }^{2}$.

\section{STJUE de 8 de mayo de 2019 [C-161/18] Villar Láiz c. INSS y TGSS. Discriminación indirecta por razón de sexo en el cálculo de la pensión de jubilación a tiempo parcial}

\section{A) Hechos del litigio principal}

22. La petición de decisión prejudicial comunitaria se plantea en el contexto de un pleito de seguridad social por el cálculo de una pensión de jubilación.

El INSS reconoció pensión de jubilación, en un importe del $53 \%$ de la base reguladora. Queda acreditado que la trabajadora había desarrollado su actividad laboral a tiempo parcial "durante una parte importante de su vida laboral" (§ 18).

La trabajadora pretende que se le aplique un porcentaje del 80,04\% tomando para ello en consideración los períodos que trabajo a tiempo parcial como si hubieran sido "periodos de trabajo a tiempo completo" (§ 20). La solicitud fue desestimada en vía administrativa.

Tras ello intimó en el órgano jurisdiccional competente una demanda judicial en la que básicamente exponía que la norma por la que se calcula su pensión era discriminatoria, en la medida en que producía "una discriminación indirecta por razón de sexo, ya que la mayoría de trabajadores a tiempo parcial eran mujeres" ( $(21)$. La petición fue desestimada en primera instancia, recurriendo ante el órgano superior funcionalmente competente, que es el que plantea la cuestión prejudicial ahora resuelta.

\footnotetext{
${ }^{2}$ Comentada por Ma A, Vicente PAlacio, "Contrato para obra o servicio determinado vinculado a la duración de la contrata (cambio de doctrina)”, Revista de Jurisprudencia Laboral, núm. 1/2019, que puede visitarse, de manera abierta y gratuita en: https://www.boe.es/biblioteca_juridica/anuarios_derecho/articulo.php?id=ANU-L-2019-00000000325
} 
El Tribunal centra el problema al apreciar que los período cotizados a tiempo parcial no se computan completos para los trabajadores que pretende jubilarse con períodos cotizados a tiempo parcial, sino únicamente en proporción a la parcialidad de la jornada que efectivamente se ha trabajado. Para ello se emplee un coeficiente de parcialidad, que pretende reflejar el porcentaje que representa la jornada efectivamente trabajada a tiempo parcial en relación con la jornada desarrollada a tiempo completo. Luego, más tarde, a los días efectivamente cotizados se le aplica un efecto multiplicador del 1,5 para averiguar los días de trabajo que se tienen en consideración para el cálculo de la pensión.

Según el proponente de la cuestión prejudicial esta reglas provocan efectos perjudiciales sobre los trabajadores a tiempo parcial, pues únicamente es técnicamente neutra para aquellos trabajadores a tiempo parcial que realizan su trabajo en un coeficiente de parcialidad igual o superior a dos tercios del tiempo completo comparable.

Puede apreciarse, estadísticamente hablando, que esta reglas de cálculo de la pensión a tiempo parcial se aplican prioritariamente a las mujeres, pues el $75 \%$ de los trabajadores jubilados habiendo trabajado a tiempo parcial son mujeres.

\section{B) Cuestión jurídica debatida}

23. El Tribunal proponente de la cuestión formula una pregunta muy directa, si la norma técnica prevista en el art. 247.a) LGSS provoca una discriminación indirecta por razón de sexo.

Lo que pretende esa norma es 'traducir' los horas de trabajo a tiempo parcial trabajadas en días cotizados, pues la norma de cálculo de la pensión se proyecta sobre los días completos cotizados, no sobre los días en que se cotizó a tiempo parcial.

Para ello utiliza un criterio, que es el denominado "coeficiente de parcialidad", que es, básicamente un dato: el porcentaje de jornada realizada a tiempo parcial en relación un trabajador idéntico a tiempo completo comparable. Ese porcentaje de jornada se aplicará sobre todos los períodos de tiempo en los que el trabajador ha estado dado de alta con contratos a tiempo parcial averiguando así el número de días efectivamente cotizados. Al número de días resultante se le aplica el multiplicador del 1,5 previsto en el art. 248.3 LGSS para averiguar los días que se tiene por cotizados para calcular la pensión de jubilación. Ese número de días finalmente cotizados es determinante de la cuantía líquida de pensión que se percibe pues cuanto mayor es más elevado el porcentaje que se aplica sobre la base reguladora, sobre la cuantía económica de lo cotizado.

Lo que cuestiona el Tribunal interno es si esta regla técnica es contraria a las normas enunciadas y, más concretamente si estas normas exigen que el número de años cotizados tenidos en consideración para determinar el porcentaje aplicable para el cálculo de la pensión se determine de la misma manera para los trabajadores a tiempo completo que para los trabajadores a tiempo parcial.

Lo que se cuestiona, en definitiva, es la forma técnica de averiguación del periodo de tiempo cotizado en trabajadores a tiempo parcial.

\section{C) Normativa UE en presencia}

24. Directiva 79/7/CEE del Consejo, de 19 de diciembre de 1978, relativa a la aplicación progresiva del principio de igualdad de trato entre hombres y mujeres en materias de seguridad social.

Directiva 2006/54/CE del Parlamento Europeo y del Consejo, de 5 de julio de 2006, relativa a la aplicación del principio de igualdad de oportunidades e igualdad de trato entre hombres y mujeres en asuntos de empleo y ocupación.

\section{D) Resolución del Tribunal}

25. Descartada la existencia de una discriminación directa (§ 36) el Tribunal de Justicia se centra en apreciar si existe discriminación indirecta, con el propósito de apreciar si las reglas jurídicas, apa- 
rentemente neutras, "sitúan a persona de un sexo determinado en desventaja particular con respecto a personas del otro sexo" (\$37), para lo que se tiene en consideración las estadísticas que acreditan que la norma "afecta negativamente a una proporción de personas de un sexo significativamente más alta que la de los personal del otro sexo" ( $§ 38$ y 39).

Respetando la competencia del órgano jurisdiccional nacional para apreciar si los datos estadísticos son ciertos ( $§ 40$ y $\S 45)$ y si se ha producido una discriminación directa o indirecta ( $§ 46)$, parece poco dudoso concluir que la mayoría de trabajadores a tiempo parcial en España son mujeres ( $\$ 42)$.

El Tribunal subraya por un lado que no se considera contrario al derecho de la Unión la aplicación de una regla de jubilación "pro rata temporis" que consienta el abono de pensión de jubilación en cuantía inferior al tiempo completo ( $(50)$ recuerda, y esta es la clave de bóveda de todo este asunto, que una regla técnica -como la aquí discutida- "que implique una reducción del importe de una pensión de jubilación de un trabajador en una proporción mayor a la correspondiente a los periodos de ocupación a tiempo parcial no puede considerarse objetivamente justificada por el hecho de que la pensión sea, en ese caso, la contraprestación de una prestación de trabajo de menor entidad" (§51).

El problema en nuestro caso no es que la base reguladora del trabajador a tiempo parcial se calcule en relación con lo cotizado, que como es menor que en un contrato a tiempo completo necesariamente va a resultar menor, sino, sobre todo, y este es el dato normativo controvertido, la aplicación al numero de días cotizado del coeficiente de parcialidad, que es el factor que refleja la relación existente entre el tiempo de trabajo a tiempo parcial trabajado en proporción a trabajo realizado por un trabajador a tiempo completo comparable (§52). Es claro que la dureza de esta última regla se suaviza multiplicando el número de días cotizados según el coeficiente de parcialidad por 1.5 (§ 53), pero no lo es menos que la utilización de este coeficiente de parcialidad "va más allá de lo necesario para alcanzar tal objetivo y representa.../... una reducción del importe de la pensión de jubilación superior a la que resultaría únicamente de tomar en consideración su jornada de trabajo pro rata temporis" (§ 55).

Por ello el Tribunal entiende que efectivamente sí se opone a la normativa comunitaria la norma interna que calcula el importe de la pensión de jubilación de un trabajador a tiempo parcial "multiplicando una base reguladora.......por un porcentaje que depende de la duración del periodo de cotización" que, a su vez, depende del "coeficiente de parcialidad" que se averigua por la relación existente en entra la jornada a tiempo parcial con la del trabajador a tiempo completo comparable, "en que esta normativa perjudique en particular a las trabajadoras respecto de los trabajadores de sexo masculino" (58).

\section{E) Apunte final}

26. Las cosas mal resueltas mal resueltas están. La problemática de la jubilación a tiempo parcial desde la perspectiva de la normativa comunitaria no es nueva. Sobre este tema ya el Tribunal de Justicia dictó la sentencia de 22 de noviembre de 2012 [C-385/11] Elbal Moreno c. INSS, cuya secuela fue la importante S TC 61/2013, de 14 de marzo, cuya doctrina fue afirmada por las SSTC 71/2013 y $72 / 2013$, de 8 de abril, y 116/2013 y 117/2013, de 20 de mayo (a las que hay que añadir su precuela: S TC 253/2004, de 22 de diciembre). La cuestión jurídica sigue siendo la misma, -antes con Elba Moreno y ahora con Villar Láiz- la aplicación de la regla "pro rata temporis" deje descolgadas a las mujeres en el acceso a una pensión digna, por más que el Real Decreto-Ley 11/2013, de 2 de agosto, para la protección de los trabajadores a tiempo parcial u otras medidas urgentes en el orden económico y social intentara, sin conseguirlo, como vemos, arreglar las cosas.

\section{STJUE de 14 de mayo de 2020 [C-55/18] Federación de Servicios CC.OO. c. Deutsche Bank. Control de la jornada diaria de trabajo, no sólo de las horas extraordinarias}

\section{A) Hechos del litigio principal}

27. La cuestión prejudicial ha sido planteada en un conflicto colectivo en el que se debatía la inexistencia de un sistema de control de la jornada diaria realizada por los trabajadores que pudiese acre- 
ditar fielmente tanto el horario efectivamente trabajado por cada trabajador, como, en su caso, la práctica de horas extraordinarias $(\S 19$ y $\S 22)$.

El sistema implantad por la empresa sí detecta las ausencias totales a los días de trabajo, así como otras incidencias como las vacaciones y los permisos retribuidos, pero no es operativo en este nivel de detalle.

La norma española interna, el art. 35.5 ET obliga a llevar un cómputo de las horas extraordinarias, pero no a apuntar fielmente el volumen de jornada realizada por cada trabajador, y la jurisprudencia del Tribunal Supremo entiende que esos sistemas de cómputo de las horas extraordinarias no pueden ser utilizados para el cálculo de la jornada, en la medida en que el ET solo lo habilita para la computación de las referidas horas extraordinarias ( $\S 24$ y 25$)$.

La Audiencia Nacional expresa sus dudas con respecto a la adecuación al ordenamiento comunitario del referido artículo del ET, apoyándose, básicamente, en dos argumentos. En primer lugar en la existencia de estadísticas fiables que acreditan que en España más de la mitad de trabajadores realizan horas extraordinarias que no se registran y, en segundo lugar, que existen informes del Ministerio de Empleo que indican que para combatir esa práctica perniciosa es necesario poder contar con un instrumento fiable de medición de la jornada del trabajador.

Entiende, más concretamente, que la interpretación que realiza el Tribunal Supremo de la exigencia de apuntar únicamente las horas extraordinarias "priva en la práctica, por un lado, a los trabajadores de un medio probatorio esencial para acreditar que su jornada laboral ha superado la duración máxima del tiempo de trabajo y, por otro, a los representantes de aquellos de un medio necesario para comprobar si se respetan las normas aplicables en la materia, lo que comporta dejar en manos del empresario el control del cumplimiento de la jornada laboral y de la observancia de los periodos de descanso" (§ 26).

\section{B) Cuestión jurídica debatida}

28. Se cuestiona si la normativa española de control de las horas extraordinarias es suficiente para garantizar las limitaciones de la duración de la jornada queridas por las normas comunitarias (§ 28), preguntando adicionalmente si no cabe deducir de dichas normas comunitarias la exigencia de implementar empresarialmente un mecanismo "de registro de la jornada diaria efectiva de trabajo", con el propósito de garantizar "garantizar el respecto efectivo de la duración máxima del tiempo de trabajo semanal y de los periodos mínimos de descanso diaria y semanal" (§ 46).

\section{C) Normativa UE en presencia}

29. Directiva 2003/88/CE del Parlamento Europeo y del Consejo, de 4 de noviembre de 2003, relativa a determinados aspectos de la ordenación del tiempo de trabajo.

Directiva 89/391/CEE del Consejo, de 12 de junio de 1989, relativa a la aplicación de medidas para promover la mejora de la seguridad y de la salud de los trabajadores en el trabajo.

\section{D) Resolución del Tribunal}

30. El Tribunal entiende que la normativa comunitaria se opone a una norma nacional que "no impone a los empresarios la obligación de establecer un sistema que permita computar la jornada laboral diaria realizada por cada trabajador" (\$ 72).

Para llegar a esa conclusión parte de la necesaria eficacia general de los mecanismos de limitación de la jornada de trabajo ( $\$ 30$ y $\S 33$ ) y de las medidas dirigidas a mejorar las condiciones de vida y trabajo de los trabajadores ( $\$ 36)$, relacionando ambos aspectos con la salud laboral y la prevención de riegos laborales (§37), y siendo conscientes de la dificultad que experimenta el trabajador para disfrutar 
efectivamente de las limitaciones horarias establecidas sin la implementación de sistemas objetivos de control ( $\S 47$ y 48). Dificultad que no se aminora porque el ordenamiento laboral prevea un mecanismos de cómputo de las horas extraordinarias (§ 52).

En definitiva que "sin un sistema que permita computar la jornada laboral diaria realizada por cada trabajador, nada garantiza.../...que se asegure plenamente a los trabajadores el respeto efectivo del derecho a la limitación de la duración máxima del tiempo de trabajo y a períodos mínimos de descanso..." (\$ 58), por lo que se patrocina que los Estados miembros impongan "a los empresarios la obligación de implantar un sistema objetivo, fiable y accesible que permita computar la jornada laboral diaria realizada por cada trabajador" (§ 60), enmarcándose dicha exigencia en los propósitos generales de las normas comunitarias de limitación de jornada y protección de la salud laboral (§ 62). Obviamente, corresponde a cada estado miembro definir "los criterios concretos de aplicación de tal sistema" (§ 63)

\section{E) Apunte final}

31. El problema cuestionado perdió interés tras la promulgación del Real Decreto-ley 8/2019, de 8 de marzo, de medidas urgentes de protección social y de lucha contra la precariedad laboral en la jornada de trabajo. Dicha norma incorpora en el art. 34.9 ET un sistema "de registro diario de jornada", que necesariamente debe incluir la concreción del "horario concreto de inicio y finalización de la jornada de trabajo de cada persona trabajadora". No exento de problemas y dificultades la verificación del tiempo de trabajo ha pasado de proyectarse hacia toda la jornada, lo cual favorece la conciliación de la vida personal y familiar, garantizando el cumplimiento en sus propios términos de las obligaciones que dimanan del contrato de trabajo.

Una sentencia que hubiera tenido una mayor proyección y operatividad en ausencia de respuesta normativa, pero que refuerza la opción política legislativa implantada.

\section{ATJUE de 12 de junio de 2019 [C-367/18] María Teresa Aragón Carrasco y otros c. Administra- ción del Estado. No indemnización por extinción de contratos eventuales de confianza}

\section{A) Hechos del litigio principal}

32. La cuestión prejudicial comunitaria se plantea en un pleito por la denegación del abono de una indemnización por el cese "libre" de las funciones que ejercían los pleiteantes como "personal eventual" con destino en los gabinetes de Presidencia, Vicepresidente y miembros del Consejo General del Poder Judicial (§ 15).

Tras solicitar la indemnización que según el ET corresponde a todos los trabajadores temporales que ven extinguido su contrato de trabajo y ver denegada su reclamación por el propio CGPJ, interponen el correspondiente procedimiento jurisdiccional impugnando dicho acuerdo en la vía ContenciosoAdministrativa.

\section{B) Cuestión jurídica debatida}

33. Los pleiteantes entienden que la negativa a indemnizar a los trabajadores eventuales por cese de la relación laboral "constituye una discriminación entre trabajadores con contrato de duración determinada y trabajadores fijos" ( $(17)$, citando como criterio de autoridad la STJUE de 14 de septiembre de 2016 [C-596/14] De Diego Porras.

La particularidad de este caso es que la cesación de los contratos se ha debido a "razones propias de los trabajadores con contrato de duración determinada" (\$ 18), cuestionando si estos trabajadores "pueden quedar excluidos de la indemnización concedida con ocasión del vencimiento del términos por el que se celebraron los contratos de duración determinada" (§ 19). 
El Tribunal proponente de la cuestión se explaya en comentar y precisar qué tipo de funciones realizan los trabajadores eventuales, dedicados no sólo a funciones prestaciones básicas, sino que asumen "funciones de gobierno que desarrollan determinados órganos del Estado" implicando "el ejercicio de funciones que, por requerir un nivel de confianza o unos conocimientos especiales, aconsejan una singular vinculación personal con el titular del órgano de gobierno que recibe la colaboración o acudir directamente a las personas que garanticen dichos conocimientos especiales" $(\S 20)$.

Pregunta, en esencia, si la normativa comunitaria se opone a la norma española que permite el libre cese sin indemnización de este tipo de personal eventual, entendiendo discriminatorio dicho trato en relación al dispensado a otros trabajadores temporales $(\S 24)$.

\section{C) Normativa UE en presencia}

34. Acuerdo Marco sobre el Trabajo de Duración Determinada, celebrado el 18 de marzo de 1999, que figura en el anexo de la Directiva 1999/70/CE del Consejo, de 28 de junio de 1999, relativa al Acuerdo Marco de la CES, la UNICE y el CEEP sobre el Trabajo de Duración Determinada.

\section{D) Resolución del Tribunal}

35. El Tribunal de Justicia aprecia que la normativa comunitaria no se opone a la normativa nacional que no prevé el abono de indemnización alguna con ocasión del cese libre del personal eventual que ejerce sus funciones de confianza o asesoramiento. Se entiende que no es una situación idéntica a la que acontece con el personal laboral fijo con ocasión de la extinción de su vínculo por causa objetiva $(\S 61)$.

Tras recordar la vigencia del principio de no discriminación entre trabajadores con contrato de duración determinada en relación con otros empleados con contratos por tiempo indefinido ( $\S 26 \mathrm{y} \S$ 31), recuerda que, en realidad, estamos en presencia de trabajadores de la Administración Pública con contratos de duración determinada ( $\$ 33)$ que han sido cesados de manera libre, cuestión sobre la que hay jurisprudencia consolidada del Tribunal de Justicia, por lo que se puede resolverse la cuestión prejudicial mediante auto (§ 29), que es lo hace (§ 30).

Subraya que el principio de no discriminación exige que no se trate de manera diferente a trabajadores en situaciones comparables (§34), por lo que procede analizar si efectivamente ambas situaciones son comparable, para lo que procede analizar "la naturaleza del trabajo, los requisitos de formación $y$ las condiciones laborales" (§ 35).

Es el Tribunal remitente de la cuestión el único competente para determinar si estamos en presencia de situaciones comparables entre los trabajadores eventuales cesado libremente y los contratados por esas misma Administración Pública de manera fija ( $(37)$, porque si apreciase que las funciones "no eran idénticas o similares" (§39) debería apreciar que ambas situaciones no son comparables. Posteriormente deberá apreciarse, en caso de que efectivamente existen diferencias de trato, si estas diferencias se encuentran objetivamente justificadas (\$ 41).

Sobre este punto aprecia que los trabajadores eventuales "no pueden albergar ninguna expectativa legítima en lo que respecta a la estabilidad de su relación de servicio, dado que son plenamente conscientes, desde el momento de su nombramiento, de la existencia de la posibilidad de ser cesados libremente en sus funciones, así como del hecho de que dicha relación concluirá, a más tardar, al final del mandato de dicha autoridad" (\$ 43).

Aprecia, por último, que el contexto en el que se produce el cese de estos trabajadores eventuales es sensiblemente diferente al que procede con la extinción de los trabajadores fijos ( $(44)$, por lo que el abono de la indemnización para los trabajadores fijos sí constituye "una razón objetiva que justifica la diferencia de trato" discutida (§47), por lo que se concluye que no existe contradicción del ordenamiento comunitario de la norma interna (§ 48). 


\section{E) Apunte final}

36. La convivencia de diferentes modalidades contractuales para la realización de un trabajo idéntico o similar suele generar diferencias de trato proclive a judicializar las extinciones producidas. El problema técnico no es la diferencia de trato que puede propiciar esa judicialización. No se trata de centrar el punto de atención en encontrar y justificar la diferencia de trato. Lo razonable, lo procedente desde un punto de vista laboral, sería que no nos encontrásemos en situaciones comparables. Es decir, que se negase el primer término de comparación. Diferentes actividades laborales se encuentran servidas por diferentes tipos de contratos. Lo esencial, por tanto, es diferenciar claramente el tipo de funciones de las que se encargan los trabajadores eventuales en relación con los fijos que trabajan para la misma Administración Pública. Con ello se conseguiría evitar los problemas de comparación que suele provocar la contratación eventual.

8. STJUE de 20 de junio de 2019 [C-72/18] Daniel Ustariz Aróstegui c. Dto. Educación Gobierno de Navarra. La percepción de un complemento retributivo en el sector de la enseñanza sólo por funcionarios es contrario a la normativa comunitaria

\section{A) Hechos del litigio principal}

37. El trabajador que da nombre a la resolución trabajaba, desde 2007, para el empleador con un contrato de derecho administrativo de duración determinada en varios centros docentes. En 2016 solicita el abono con efectos retroactivos de cuatro años del "complemento retributivo del grado" que perciben únicamente los profesores funcionarios con la misma antigüedad, según la norma autonómica que lo regula (§ 15). Tras ver desestimada su pretensión en vía administrativa recurre jurisdiccionalmente.

El Juzgado de lo Contencioso-Administrativo competente entiende que el recurrente sí cumple con los requisitos objetivos de la convocatoria del complemento, pero "no cumple el requisito subjetivo relativo a la condición de funcionario" (\$19), aunque repara en que "no existe ninguna diferencia entre las funciones, los servicios y las obligaciones profesionales asumidos por un profesor funcionario y los asumidos por un profesor contratado" en régimen de derecho Administrativo (§ 20).

\section{B) Cuestión jurídica debatida}

38. El Magistrado pregunta, en esencia, si la norma patria que reserva el percibo del complemento económico únicamente a los funcionarios se opone a la norma comunitaria, o si, por el contrario, dicho complemento constituye una retribución de la carrera profesional propia y exclusiva de los funcionarios.

\section{C) Normativa UE en presencia}

39. Acuerdo Marco sobre el Trabajo de Duración Determinada, celebrado el 18 de marzo de 1999, que figura en el anexo de la Directiva 1999/70/CE del Consejo, de 28 de junio de 1999, relativa al Acuerdo Marco de la CES, la UNICE y el CEEP sobre el Trabajo de Duración Determinada.

\section{D) Resolución del Tribunal}

40. El Tribunal de Justicia entiende que la norma autonómica que reserva el derecho a un complemento retributivo únicamente a los funcionarios de carrera, excluyendo a los trabajadores contratados en otro régimen (Administrativo, en este caso) es contraria a la normativa comunitaria 
El Tribunal de Justicia afirma, después de recordar que la no discriminación en las condiciones de trabajo es un principio del derecho comunitario (\$23) y que las cuestiones salariales se consideran condición de trabajo ( $\$ 25)$, que el hecho de que el único requisito objetivo para el percibo del complemento sea "haber cubierto un tiempo de servicio" determina que "este se abona precisamente por razón de la relación de servicio" (§ 27).

Las líneas de defensa del Gobierno de Navarra y del Gobierno Español muestra hasta qué punto falta camino por recorren en estas cuestiones, pues se centran, respectivamente, en afirmar que efectivamente el complemento está previsto únicamente para funcionarios $(\S 29$ y $\S 42)$ y que del complemento también están excluidos los "docentes empleados por tiempo indefinido" (§30).

La línea argumentativa el Tribunal pasa, como en otros casos similares a este, en cuestionar si estamos en presencia de situaciones comparables (§33), y si, una vez afirmado que efectivamente se está en presencia de situaciones comprables, si existe alguna razón objetiva que justifica la diferencia de trato $(\S 39)$.

El Tribunal precisa que los Estados sí pueden, en usos de sus competencias, establecer requisitos de antigüedad para acceder a determinados puestos de trabajo ( $(43)$ pero implementar "un requisito genérico y abstracto según el cual una persona debe ser funcionario de carrera para poder tener derecho a una condición de trabajo como la controvertida en el litigio principal, sin que se tomen en consideración, especialmente, la naturaleza particular de las tareas que se han de realizar ni las características inherentes a ellas, no se corresponde con las exigencias de la jurisprudencia" comunitaria evacuada en relación a la Directiva de tiempo de trabajo determinaod alegada (\$ 44$)$.

En definitiva, se entiende que no existe "ninguna razón objetiva" que permita "justificar la exclusión de los contratados administrativos que hayan cubierto el tiempo de servicios requerido del derecho al complemento retributivo controvertido" (§ 49).

\section{E) Apunte final}

41. La implementación de determinados complementos económicos que sólo tengan en consideración el tiempo de permanencia en la empresa debe, razonablemente, beneficiar a todos los trabajadores que cumplan objetivamente dichas condiciones temporales, sin reparar en las particularidades del sistema de contratación de dichas funciones, sea en régimen de derecho Administrativo, laboral o funcionarial. O dicho de otra manera, si lo que se pretende es implementar un complemento retributivo que sólo alcance a los funcionarios debe organizarse desde los diferentes tipos de actividades profesionales que ellos realicen: responsabilidad, organización del servicio, etc., no desde parámetros objetivos que puedan cumplir otros trabajadores de diferente tipo.

\section{STJUE de 20 de junio de 2019 [C-404/18] Jamina Hakelbrachty Tine Vandenbon c. WTG Retail $B V B A$. Tutela antidiscriminatoria refleja por embarazo a testigos del proceso de contratación}

\section{A) Hechos del litigio principal}

42. La cuestión prejudicial que resuelve esta sentencia tiene por objeto la concesión de una indemnización por despido en el ordenamiento jurídico belga. La señora Vandebon es empleada de WTG y en dicha condición entrevista a la señora Hakelbracht para un puesto de trabajo en junio de 2015 en cuyo desarrollo comenta que se encuentra embarazada. A pesar de ello entiende que es la candidata idónea para el puesto e informa a la mercantil WTG de ello. La gestión administrativa de la contratación informa a la señora Vandenbon que no va a ser contratada "debido a su embarazo" (§ 11).

La señora Vandenbon informa su empresa de que la ley belga prohíbe que se rechace una contratación por esta circunstancia (\$ 12), pasando posteriormente a informar a la señora Hakelbracht de que no ha sido contratada precisamente por encontrarse embarazada. Acto seguido la señora Hakelbracht se pone en contacto con WTG informando a la mercantil de que va a recurrir la decisión de no contratarla, 
al entenderla irregular. Después de una entrevista con el responsable de WTG (§ 15) en octubre de 2015 decide interponer acciones legales contra la empresa.

En abril de 2016 la señora Vandenbon fue despedida por WTG (§ 17). En la reclamación que intima la trabajadora la empresa WTG justifica la extinción en motivos estrictamente laborales.

Tanto la señora Vandenbon como la señora Hakelbracht intiman de la empresa WTG el abono de una indemnización a tanto alzado en la cuantía de seis meses de salario. No se alcanza un acuerdo y se acude a los tribunales. En el procedimiento jurisdiccional se acredita que la señora Hakelbracht ha sufrido una "discriminación directa por razón de sexo" por lo que se le otrora una indemnización reparadora (§ 19).

La pretensión de la señora Vandenbon se justifica en la norma interna Belga de lucha contra la discriminación entre hombre y mujeres que entiende como una medida perjudicial "la ruptura de la relación laboral" (\$ 9) entendiendo que ha sido su condición de testigo en el expediente extintivo de la señora Hakelbracht el que ha propiciado la extinción unilateral por parte del empresario de su contrato de trabajo (§ 20). El Tribunal proponente de la cuestión prejudicial aprecia que no se dan, según la definición que emplea la norma Belga, las condiciones para amparar a la señora Vandenbon como testigo, pues esta "no puede presentar ningún documento fechado y firmado relativo a su testimonio" (§ 20).

\section{B) Cuestión jurídica debatida}

43. El Tribunal Belga se pregunta si la protección dispensada por la norma Belga no es más restrictiva que la Comunitaria que, en su opinión, protege no sólo a los "testigos oficiales" sino que también debe "extenderse a las personas que defiendan o apoyan a la persona que ha presentado una reclamación por discriminación por razón de sexo" (§ 21).

La cuestión prejudicial pregunta si la norma comunitaria se opone a la nacional con concede protección a las personas que intervengan como testigos "exclusivamente a las personas que.../...ponen en conocimiento de la persona contra la que se han presentado la reclamación, en un documento firmado y fechado, los hechos que ellas mismas han visto u oído" (\$22).

\section{C) Normativa UE en presencia}

44. Directiva 2006/54/CE del Parlamento Europeo y del Consejo, de 5 de julio de 2006, relativa a la aplicación del principio de igualdad de oportunidades e igualdad de trato entre hombres y mujeres en asuntos de empleo y ocupación.

Directiva 92/85/CEE del Consejo, de 19 de octubre de 1992, relativa a la aplicación de medidas para promover la mejora de la seguridad y de la salud en el trabajo de la trabajadora embarazada, que haya dado a luz o en período de lactancia.

\section{D) Resolución del Tribunal}

45. El Tribunal de Justicia aprecia que la normativa comunitaria sí se opone a la nacional que solamente protege al trabajador testigo que ha prestado apoyo en un procedimiento de discriminación por razón de sexo de manera formal, considerando, en definitiva, que la tutela antirepresalia también alcanza al tipo de testimonio prestado en este procedimiento (§ 38$)$.

Considera el Tribunal, en primera lugar, que la no selección de la candidata al puesto de trabajo por estar embarazada efectivamente debe considerarse como un trato menos favorable ( $(25)$, precisando que la categoría de trabajadores que pueden acogerse a la norma comunitaria debe entenderse en sentido amplio, incluyendo "a todos los trabajadores que pueden ser objeto de medidas de represalia tomadas por el empresario como reacción a una reclamación presentada por una discriminación basada en el sexo" (§ 27), interpretación amplia que se ve corroborada por el objetivo de la propia norma comunitaria $(\S 30)$. 
Precisa el Tribunal que la norma comunitaria que pretende la eliminación de las discriminaciones laborales basadas en el sexo carecería de eficacia si no "cubriera las medidas que un empresario podría tomar contra trabajadores que, de manera formal o informal, hubieran defendido a la persona protegida o hubieran declarado como testigos a su favor" (§ 34)

\section{E) Apunte final}

46. La consecuencia que se extrae de la resolución es que la tutela antidiscriminatoria pretendida por las normas -comunitarias y nacionales de los estados miembros- así como las garantías jurídico técnicas implementadas para la protección de los trabajadores puede abarcar no sólo a los trabajadores o trabajadores directamente susceptibles de ser discriminados por sus circunstancias (personales, culturales, sociales, etc.) sino también a quienes coadyuvan a la consecución de los objetivos de las antidiscriminatorias, especialmente los testigos o cooperadores del empresario en el ámbito laboral.

La doctrina recuerda ligeramente a la que en similar sentido se deduce de la STJUE de 17 de julio de 2008 [C-303/06] Coleman c. Attridge Law y Steve Law, en un supuesto de discriminación por discapacidad a una trabajadora que no era discapacidad pero sí tenía un hijo que sí era discapacitado, precisando que el ámbito de protección de la norma también alcanza a quien no siendo discapacitado tiene que ocuparse de un familiar que sí lo es. Una especie de tutela 'refleja' que ahora se reitera para otros sujetos no amparados directamente por la norma.

\section{STJUE de 11 de septiembre de 2019 [C-397/8] DW c. Nobel Plasquiques Ibérica. Absentismo por motivos de discapacidad y despido por faltas de asistencia al trabajo}

\section{A) Hechos del litigio principal}

47. El caso que resuelve esta resolución ha perdido toda su importancia, porque el legislador español ha derogado en febrero de 2020 el precepto que regulaba la modalidad de despido cuestionada en esta resolución.

Con todo la explicación de que ha sucedido tiene interés y relevancia, sobre todo para encajar y comprender la trascendencia de la modificación legislativa y explicar el devenir de los acontecimientos jurídicos que se sucedieron ${ }^{3}$.

La sentencia objeto de comentario resuelve una cuestión prejudicial planteada por el JS núm. 3 de Barcelona mediante auto de 30 de mayo de 2018 en un litigio por despido por causas objetivas entre la trabajadora $D W$ y la empresa Nobel Plastiques.

La trabajadora $D W$ fue contratada por Nobel Plastiques Ibérica en 2004. Siete años más tarde se le diagnosticó epicondilitis, dolencia de la que fue intervenida al año siguiente. La lesión tiene la consideración de enfermedad profesional, y desde que enfermó se la ha reconocido como "trabajadora especialmente sensible a los riesgos derivados del trabajo" según las previsiones de la LPRL.

Desde la fecha en la que enfermó hasta 2014 la trabajadora estuvo en varias ocasiones en incapacidad temporal, diagnosticándole también algunos episodios de "trastorno de ansiedad" relacionados con su dolencia. En varias ocasiones intimó tanto al servicio médico como a la empresa que se adecuara su puesto de trabajo a la condición física que padecía, no obteniendo una respuesta satisfactoria.

La empresa formaliza un despido por causas objetivas, en cuyo devenir jurisdiccional se plantea la cuestión prejudicial ahora resuelta por la sentencia objeto de comentario.

\footnotetext{
${ }^{3}$ Un comentario a la resolución puede verse en A.Arias Domínguez, “¿Puede ser considerada persona con discapacidad la trabajadora que tiene la consideración de especialmente sensible frente a los riesgos derivados del trabajo?", Revista de Jurisprudencia Laboral, núm. 8/2019, en el sitio web: https://www.boe.es/biblioteca_juridica/anuarios_derecho/articulo.php?id=ANUL-2019-00000000706
} 


\section{B) Cuestión jurídica debatida}

48. Concretamente se cuestiona si el concepto de "trabajadores especialmente sensibles a determinados riesgos", en la caracterización técnica que se deduce del art. 25 LPRL, es asimilable al concepto de "discapacidad" que emplea la Directiva 2000/78. Porque si efectivamente tuviese esa consideración su inclusión en el expediente extintivo quedaría en entredicho.

Desde otro punto de vista, aunque inextricablemente unido con esta argumentación, también se cuestiona la validez de los criterios que se han implementado por la empresa para determinar qué trabajadores van a ser incluidos en dicho expediente, especialmente si tienen en consideración los elementos que se relacionan con los ajustes razonables que debían proporcionarse para facilitar la adaptación al puesto de trabajo de trabajadores especialmente sensibles a los riesgos laborales. El Magistrado proponente de la cuestión asume que uno de los criterios utilizados, el referido al puesto de trabajo que desarrolla, es objetivo y neutro, y no provoca discriminación alguna. Sin embargo los otros tres empleados (el relativo a la productividad durante el año 2016, el referido a la polivalencia en el puesto de trabajo, y el que mide el nivel de absentismo en el año 2016) sí pueden provocar -a su juicio- una discriminación indirecta.

Plantea, en definitiva, cuatro cuestiones prejudiciales, reconducibles a las dos principales siguientes.

En primer lugar, si puede ser considerada persona con discapacidad (desde la perspectiva de la aplicación de la Directiva 2000/78) la persona trabajadora calificada como especialmente sensibles a los riesgos del trabajo.

Y, para el supuesto de que efectivamente así se considerase, plantea el proponente otras tres cuestiones, reconducibles a un único enunciado, que es como lo resuelve la sentencia comentada: ¿Constituye un acto de discriminación la decisión de despedir a una trabajadora (por causas económicas, técnicas, organizativas y de producción), cuando tiene reconocida una discapacidad precisamente por haber sido categorizada como especialmente sensible a los riesgos laborales por causa de las dolencias físicas que le han provocado períodos de ausencias por baja médica antes del despido?.

\section{C) Normativa UE en presencia}

49. Directiva 2000/78/CE del Consejo, de 27 de noviembre de 2000, relativa al establecimiento de un marco general para la igualdad de trato en el empleo y la ocupación.

\section{D) Resolución del Tribunal}

50. El Tribunal entiende que el trabajador especialmente sensible a los riesgos laborales solo se considera trabajador discapacitado desde la óptica de la Directiva 2000/78 en el caso de que el estado de salud implique una limitación de su capacidad que puedan impedir la participación plena y efectiva del trabajador en la vida profesional en igualdad de condiciones con otros trabajadores, correspondiendo al órgano jurisdiccional nacional corroborar si en el asunto sometido a su jurisdicción concurren tales circunstancias.

La concreción de los elementos que se tienen en consideración para la determinación de los trabajadores especialmente sensible a los riesgos del trabajo se organizan sobre parámetros diferentes a los que se emplean para apreciar la discapacidad del sujeto, por lo que la equiparación de ambas situaciones jurídicas no es del todo homogénea, de lo que seduce que no siempre y en todo caso el trabajador especialmente sensible tiene que ser considerado persona con discapacidad desde la perspectiva de la Directiva europea.

Los cuatro criterios implementados empresarialmente para organizar el despido por circunstancias económicas técnicas organizativas y de producción son aparentemente neutros. Sin embargo uno de ellos, el relacionado con el absentismo, puede, indirectamente, dañar al trabajador discapacitado ya que este tipo de trabajadores están más expuestos al riesgo de tener un índice elevado de absentismo que un trabajador sin discapacidad. También el criterio que se relaciona con la productividad está en cuestión 
pues, por la misma razón, los trabajadores discapacitados tienen limitaciones que pueden concretarse en una menor productividad.

La Directiva exige, por último, que el empresario realice ajustes razonables para permitir a las personas con discapacidad acceder al empleo, mantenerlo y desarrollarlo sin limitaciones, siempre que eso no suponga "una carga excesiva para el empresario", circunstancia cuya apreciación corresponde al juez nacional.

\section{E) Apunte final}

51. La doctrina que emana de esta resolución ha perdido todo su interés tras la promulgación del Real Decreto-ley 4/2020, de 18 de febrero, por el que se deroga el despido objetivo por faltas de asistencia al trabajo establecido en el artículo 52.d) del texto refundido de la Ley del Estatuto de los Trabajadores, aprobado por el Real Decreto Legislativo 2/2015, de 23 de octubre.

A pesar de que la operatividad del motivo se integraba por más causas que la enfermedad del trabajador y del rol que jugaba de contención del absentismo en la empresa la fuerza política de una promesa electoral obró el efecto. Probablemente los acontecimientos se precipitaron tras la desafortunada STC 118/2019, de 16 de octubre. En ella, dictada en un caso completamente diferente a éste, se mantiene, básicamente, que la posibilidad de extinguir un contrato de trabajo por enfermedad del trabajador encuentra acomodo constitucional en la salvaguarda de la productividad de la empresa. No es una resolución muy afortunada, no tanto por la conclusión a la que llega, la constitucionalidad del despido objetivo por absentismo, sino por la argumentación que emplea, que no es la más afortunada.

Con la derogación del art. 52.d) ET se conseguían, en definitiva, dos objetivos: canalizar el rédito político de la lucha contra la reforma laboral de 2012, sabiamente orquestada por los medios periodísticos gubernamentales a pesar de constituir una abierta mentira jurídica, y detener la imaginaria Lawfare que había comenzado, según las imaginaciones calenturientas gubernamentales, el Tribunal Constitucional. El embuste jurídico tendrá el recorrido que dure el reconocimiento como despido improcedente de las extinciones basada por estas causas, porque el legislador no quiso considerar a este supuesto como un caso de nulidad del despido. Eso sí hubiera tenido eficacia para la consecución del objetivo político que se decía perseguir, aunque hubiera sido difícil orquestarlo técnicamente y venderlo mediáticamente. El análisis de su operatividad para el mercado de trabajo poco importa, pero a lo más que se ha llegado es a encarecer la extinción por enfermedad del trabajador.

\section{STJUE de 18 de septiembre de 2019 [C-366/18] Ortiz Mesonero c. UTE Luz Madrid. Adscrip- ción a turno de trabajo para la conciliación de la vida familiar y laboral}

\section{A) Hechos del litigio principal}

52. El señor Ortiz Mesonero trabaja para la mercantil UTE Luz Madrid. Solicita de su empresa el establecimiento de un horario de trabajo fijo para poder dedicarse al cuidado de sus hijos, pues la empresa ha implementado, con carácter general, un régimen de trabajo a turnos en tres turnos en el que el demandante va rotando en un horario variable $(\S 15)$.

El trabajador solicita, en definitiva, que se le adscriba "exclusivamente en el turno de mañana" con las mismas condiciones salariales y el mantenimiento del mismo volumen de horas de trabajo, siendo denegada su solicitud por el empresario $(\S 16)$ e interponiendo seguidamente el correspondiente procedimiento judicial en el curso del cual se ha planteado la presente cuestión prejudicial.

De manera un tanto peculiar el juez competente muta el objeto de la pretensión (uria novit curia) y en vez de resolver el asunto sometido a su jurisdicción con apoyo en el art. 34.8 ET alegado por el trabajador que trata de organizar la distribución de jornada, entiende que lo que el demandante solicita, en realidad, es una reducción de jornada regulada en el art. 37.6 ET con el objeto de conciliar vida familiar y laboral ( $\S \S 18$ y 19), pues aprecia que el ordenamiento patrio no permite acoger una 
pretensión como la intimada por el demandante, es decir que el ordenamiento no regula la adscripción a un régimen concreto del sistema de turnos por motivos familiares sin llevar aparejada, siempre y en todo caso, una reducción de jornada, con la consiguiente reducción del salario (§ 20). Se trata, por tanto, de un problema de ausencia de regulación, de una cuestión no regulada en la Ley, a la que, dicho sea de paso, tampoco el Convenio Colectivo dedica atención alguna regulando, como puede hacerlo, la forma técnica de satisfacer esa necesidad de conciliar vida familiar y trabajo.

El órgano jurisdiccional aporta a la cuestión que plantea estadísticas sobre el volumen de varones que solicitan medidas laborales de conciliación (§ 21) con el objeto de cuestionar si la aplicación técnica de la norma española provoca una discriminación indirecta por razón de sexo (§ 22).

\section{B) Cuestión jurídica debatida}

53. El problema jurídico debatido versa sobre si se opone a la normativa comunitaria una norma como la nacional que no permite la adscripción directa a un determinado turno de trabajo para la conciliación de la vida familiar y laboral sin que deba para ello reducirse obligatoriamente la jornada ordinaria de trabajo $(\S 25)$.

\section{C) Normativa UE en presencia}

54. Directiva 2006/54/CE del Parlamento Europeo y del Consejo, de 5 de julio de 2006, relativa a la aplicación del principio de igualdad de oportunidades e igualdad de trato entre hombres y mujeres en asuntos de empleo y ocupación.

Directiva 2010/18/UE del Consejo, de 8 de marzo de 2010, por la que se aplica el Acuerdo marco revisado sobre el permiso parental, celebrado por BUSINESSEUROPE, la UEAPME, el CEEP y la CES, y se deroga la Directiva 96/34/CE.

\section{D) Resolución del Tribunal}

55. Después de rechazar la queja de inadmisibilidad planteada por el Gobierno Español (§ 26), y de declarar inadmisible la cuestión relativa a la discriminación indirecta por razón de sexo ( $\$ 40)$, el Tribunal de Justicia afirma que la Directiva sobre permiso parental no se aplica a un supuesto como el debatido en este procedimiento ( $§ 53)$.

Básicamente aprecia que la normativa de la Unión invocada tiene como presupuesto de operatividad que el trabajador "se encuentre en una situación de reincorporación de un permiso parental" (§ 47), siendo importante subrayar que las normas comunitarias no regulan de manera expresa la cuestión aquí controvertida, es decir, la adscripción a un turno fijo para conciliar vida familiar y laboral cuando el "régimen de trabajo habitual es un régimen de turnos con horario variable" (§ 48).

Pues bien, es evidente que el trabajador no se ha 'reincorporado' tras el disfrute de un permiso parental, y también lo es que la normativa de la Unión no regula la situación comprometida.

\section{E) Apunte final}

56. El resultado al que llega la resolución objeto de comentario necesariamente es insatisfactorio. Deja imprejuzgada una cuestión muy concreta que provoca un desarreglo en la conciliación del trabajador. No sólo no da satisfacción al demandante en una pretensión de los más razonable, sino que la argumentación que emplea es pobre y de vuelo corto. Pobre por su escasez y falta de desarrollo. De vuelo corto porque necesariamente, a no mucho tardar, tendrá que asumir que a este tipo de pretensiones tiene que dar respuesta, incluso aunque la normativa comunitaria no las regula de manera concreta y precisa. 
Porque desde el punto de vista de la normativa comunitaria no parece razonable que no se conteste al fondo de la cuestión basándose en que las normas de protección de los permisos parentales sólo son aplicables a los trabajadores que se reincorporen al trabajo tras el disfrute de los permisos previstos en las normas. Básicamente porque lo que está pidiendo el trabajador es, precisamente, el disfrute de un derecho de conciliación. Y a esta cuestión el Tribunal responde, sin más, afirmando que esta no es una cuestión regulada en la normativa comunitaria. No parece razonable que en una jurisprudencia tan creativa como la del Tribunal de Justicia no se encuentre un asidero conceptual, una exposición de motivos, un procedente jurisprudencial al que agarrarse para construir un argumentario más desarrollado, más completo, que permite, cuanto menos, volver a plantear la cuestión desde otro punto de vista, desde otra perspectiva, en una futura cuestión prejudicial nueva.

Desde el punto de vista del derecho nacional cuestionado llama la atención que la alegación del trabajador no haya justificado su pretensión en el principio de adaptación del trabajo a la personal del trabajador, incluido en el art. $36.5 \mathrm{ET}$, de mucho juego dogmático aunque de escaso desarrollo práctico. Es cierto que la norma patria no

Es importante precisar que la regulación que contiene los derechos de los trabajadores a los permisos laborales retribuidos, básicamente el art. 37 ET también se dedica a regular reducciones de jornadas por motivos familiares. Quizá el nuevo ET debiera organizar esta materia diferenciando ambas instituciones, para facilitar la operatividad de las nuevas realidades laborales que al regularse de forma conjunta dificulta un tanto la aplicación de situaciones no previstas expresamente.

Por ultimo conviene subrayar el rol que el convenio colectivo juega en la determinación de este tipo de derecho, pobre en este caso concreto, pero insuficiente en la mayoría de ocasiones. Aunque es una materia tradicional no suelen contener innovaciones importantes en esta cuestión.

\section{ATJUE de 15 de octubre de 2019 [C-439/18 y C-472/18] $O H$ y $E R$ c. $A E A T$. Devengo de trienios de fijos-discontinuos}

\section{A) Hechos del litigio principal}

57. La cuestión prejudicial que se resuelve mediante el siguiente auto ha surgido en un litigio (entre las partes identificadas) con ocasión del cálculo de la antigüedad como trabajadoras fijas-discontinuas a efectos de percibir trienios como complemento económico relacionado con la antigüedad en la empresa. Es de destacar que AEAT es una empresa pública y que cuenta con un convenio colectivo que regula la figura de los trabajadores fijos-discontinuos así como el complemento económico cuestionado.

Ambas trabajadoras (OH y ER) fueron contratadas bajo la modalidad contractual de referencia para un determinado período de tiempo (campaña de la renta), contratación que se repetía cada año. En mayo de 2015 presentaron ambas reclamaciones con el objeto de que se les reconociera la antigüedad "los efectos de la adquisición del derecho a percibir trienios.../...y en consecuencia a una promoción económica y profesional" (§ 18.)

Las solicitudes fueron denegadas en vía administrativa, básicamente por entender que el Convenio Colectivo aplicable excluía expresamente "los periodos no trabajados" de los trabajadores fijos discontinuos del cómputo de la antigüedad.

La pretensión de tutela jurisdiccional de su derecho fue rechazada en primera instancia, recurriéndose en suplicación, en cuyo procedimiento se plantea la cuestión prejudicial ahora resuelta.

El Tribunal nacional cuestiona la aplicación a este caso de la regla pro rata temporis contenida en el Convenio Colectivo aplicable, según la cual los efectos retributivos y promocionales de la antigüedad en la empresa de los trabajadores a tiempo parcial con distribución de su jornada anualmente debe atenderse única y exclusivamente "al tiempo de prestación de servicios" (§23). La cuestión consiste en determinar si la antigüedad debe abarcar todo el tiempo de permanencia en la empresa, aunque por su modalidad contractual hayan existido períodos de no actividad laboral.

Aprecia el Tribunal, más como complemento de la argumentación y seguramente para dar cabida a la tutela antidiscriminatoria, que de las estadísticas sobre trabajadores de esta modalidad contractual 
puede deducirse una discriminación indirecta, pues son muchas más mujeres que hombres las contratadas bajo la misma (§ 22).

\section{B) Cuestión jurídica debatida}

58. El problema jurídico básico consiste en determinar si para el percibo de los complementos económicos relacionados con la antigüedad debe computarse únicamente el período de tiempo efectivamente trabajado o si, por el contrario, debe computarse la totalidad del tiempo transcurrido desde el comienzo de la relación laboral (\$20), porque se constata que para los trabajadores a tiempo completo la antigüedad se data en el momento del comienzo de la relación laboral, mientras que para los contratados a tiempo parcial sólo se tiene en cuenta para dicha antigüedad los períodos de tiempo efectivamente trabajados (§36 y $\S 37$ y 38$)$.

\section{C) Normativa UE en presencia}

59. Directiva 97/81/CE del Consejo, de 15 de diciembre de 1997, relativa al Acuerdo Marco sobre el Trabajo a Tiempo Parcial concluido por la UNICE, el CEEP y la CES.

Directiva 2006/54/CE del Parlamento Europeo y del Consejo, de 5 de julio de 2006, relativa a la aplicación del principio de igualdad de oportunidades e igualdad de trato entre hombres y mujeres en asuntos de empleo y ocupación.

\section{D) Resolución del Tribunal}

60. El Tribunal de Justicia tiene claro que la normativa de la Unión sí se oponen a una normativa y a una práctica empresarial que para los trabajadores fijos discontinuos computa la antigüedad requerida para lucrar complementos económicos teniendo presente únicamente "los periodos efectivamente trabajados", excluyéndose "los periodos en los que no se ha trabajado" si esa consecuencia (normativa y práctica) no se predica para "el caso de los trabajadores a tiempo completo" (§ 51, y § 64).

El Tribunal resuelve por auto porque la normativa procesal comunitaria indica que esa es la fórmula técnica de resolución "cuando una cuestión prejudicial sea idéntica a otra sobre la que el Tribunal ya haya resuelto" (\$ 24).

Se considera fundamental apreciar que esta forma de cómputo de la antigüedad no se emplea para los trabajadores contratado "a tiempo completo" (\$26). Obviamente se parte de la base de que los complementos económicos debatidos en este procedimiento constituyen, efectivamente, una condición de empleo $(\S 30)$.

El Tribunal procede a analizar si la exclusión del cómputo de la antigüedad de los períodos no trabajados de estos trabajadores a tiempo parcial constituye un trato "menos favorable" que los trabajadores a tiempo completo que se encuentran en situación comparable (§ 32). Aprecia que, en realidad, ejercen un trabajo idéntico y requieren idénticas condiciones formativas para realizarlo ( $\$ 34)$, por lo que no se duda de que, efectivamente, los trabajadores a tiempo parcial se encuentran en situación comparable con los contratados a tiempo completo (§ 35).

El Tribunal entiende, en un requiebro no fácil de apreciar, que aunque ya ha evacuado jurisprudencia que permite en casos similares a este "una reducción proporcionada de sus derechos a un componente de la retribución" (§ 42) la regla pro rata temporis "no es aplicable a la determinación de la fecha de adquisición de un derecho a un componente de la retribución, en la medida en que esta depende exclusivamente de la duración de la antigüedad adquirida por el trabajador" (\$ 43)

Lo esencial es entender que el complemento económico debatido tiene en consideración la antigüedad en el trabajo no la cantidad de actividad laboral realizada (u otras condiciones), por lo que el Tribunal no se opone a que, como se precisa, puedan existir diferentes complementos económicos que 
premien la intensidad de trabajo o la dedicación. Lo que proscribe es que el que tiene en cuenta la antigüedad compute de diferente manera según el tipo de contrato de que se trate, indefinido o a tiempo parcial. No hay, por tanto, razones objetivas que justifiquen esta diferencia de trato ( $\S \S 46$ y 50).

El Tribunal también asume, con argumentaciones muy conocidas que no es necesario destacar en este momento, que la medida normativa y la práctica empresarial erosionan el principio de igualdad de trato en perjuicio de las mujeres ( $\$ 59)$ al poder apreciarse que la medida normativa que regula el complemento retributivo, aunque bien es cierto que redactado de forma neutra, perjudica "de hecho a un número mucho mayor de mujeres que de hombres" (§ 54).

\section{E) Apunte final}

61. Lo que pretende asegurar la resolución es que no se produzcan formas diferentes de computar la antigüedad dependiendo del tipo de contrato laboral que tengan los trabajadores. Lo que supone, básicamente, que si un complemento económico se regula única y exclusivamente teniendo presente la antigüedad el comienzo del cómputo de la misma tiene que ser idéntico para los trabajadores a tiempo completo que para los contratados a tiempo parcial.

Pero la resolución no niega que puedan existir, aplicando la regla pro rata temporis, diferentes complementos retributivos que tengan en consideración otras variables para premiar económicamente la intensidad productiva, o el volumen de trabajo. La negociación colectiva tiene, por tanto, un fructífero campo en el que desarrollar las potencialidades que la norma concede en este sentido.

\section{STJUE de 7 de noviembre de 2019 [C-396/18] Gennaro Cafaro c. DQ. Discriminación laboral por motivos de edad}

\section{A) Hechos del litigio principal}

62. El señor Gennaro ha trabajado para la empleadora como piloto de aeronaves. Al cumplir sesenta años de edad se ha extinguido de manera automática su contrato de trabajo por así disponerlo una norma interna del ordenamiento jurídico italiano. La decisión se recurrió ante los órganos judiciales competentes. En primera instancia su pretensión fue desestimada. Recurrida en apelación el Tribunal apreció, básicamente, que el trabajador no había sido despedido, sino que su contrato se había extinguido automáticamente por la aplicación de una norma legal que así lo preveía (§ 20). Frente a dicha decisión impetró el correspondiente recurso de casación en el que se ha originado la cuestión prejudicial que aborda la sentencia ahora comentada.

\section{B) Cuestión jurídica debatida}

63. Se plantean dos cuestiones jurídicas. La primera, sin especial interés para nosotros, sobre el alcance de la excepción a la extinción obligatoria por cumplimiento de edad que permite la normativa únicamente para el transporte aéreo comercial (§ 23).

En segundo lugar sobre si la norma interna italiana puede considerarse discriminatoria por razón de edad en relación al empleo y la ocupación $(\S 25$, y $\S 33)$.

\section{C) Normativa UE en presencia}

64. Reglamento (UE) n. ${ }^{\circ} 1178 / 2011$ de la Comisión, de 3 de noviembre de 2011, por el que se establecen requisitos técnicos y procedimientos administrativos relacionados con el personal de vuelo de la aviación civil. 
Directiva 2000/78/CE del Consejo, de 27 de noviembre de 2000, relativa al establecimiento de un marco general para la igualdad de trato en el empleo y la ocupación

\section{D) Resolución del Tribunal}

65. El Tribunal entiende que las normas de la Unión no se oponen a una norma nacional que prevé la extinción obligatoria de la relación laboral de pilotos de aeronaves por cumplimiento de los sesenta años de edad, "siempre que tal normativa sea necesaria para la seguridad pública", circunstancia que corresponde aprecia al órgano jurisdiccional interno (§ 73). Matiz este último que mediatiza por completo la operatividad del fallo.

La protección de la seguridad aérea es el propósito que ha inspirado la norma italiana (§ 47) cuya legitimidad se aprecia sólo si efectivamente es necesaria para la consecución del objetivo pretendido (§ 49) y no provoca una discriminación por razón de edad.

El Tribunal aprecia que una norma como la controvertida no será discriminatoria cuando, "debido a la naturaleza de la actividad profesional concreta de que se trate o al contexto en que se lleve a cabo, dicha caracteristica constituya un requisito profesional esencial y determinante, siempre y cuando el objetivo sea legítimo y el requisito, proporcionado" (\$ 58).

Para calibrar estos intereses tiende que tenerse presente que los pilotos de líneas aéreas deben poseer una "capacidad fisicas especificas" que naturalmente "disminuye con la edad" (\$60), erigiéndose, en definitiva, un "requisito profesional esencial y determinante" para el ejercicio de la profesión de piloto de líneas aéreas ( $(62)$.

El debate se desplaza, una vez asumido que la normativa italiana persigue un propósito legítimo, y razonable, a la apreciación de si la extinción obligatoria constituye la implementación de una consecuencia proporcionada para la consecución del objetivo (§ 65).

A pesar de que el propio Tribunal de Justicia consideró en la sentencia de 13 de septiembre de 2011 [C 447/09] Prigge y otros, que la fijación en sesenta años de edad la de extinción del contrato para este tipo de trabajadores era un "requisito desproporcionado" (§ 68) aprecia que esa solución no puede extrapolarse al asunto aquí debatido (§ 69), pues los trabajadores de la mercantil DQ "normalmente deben actuar en condiciones dificiles, o incluso extremas, por lo que la realización de estas operaciones exige unos requisitos fisicos especialmente altos" (\$ 55).

En definitiva, el Tribunal aprecia que corresponde al órgano jurisdiccional interno apreciar si dados los intereses en juego y la actividades que desarrollan los pilotos la normativa nacional interna se considera o no proporcionada (\$ 70), teniendo presente que, en principio, la normativa de la Unión no se opone a la operatividad de una norma como la italiana aquí debatida (§ 72).

\section{E) Apunte final}

66. La jubilación obligatoria por motivos de edad se aprecia en nuestro ordenamiento para este tipo de trabajadores en el Real Decreto 1559/1986, de 28 de junio, por el que se reduce la edad de jubilación del personal de vuelo de trabajos aéreos, estableciendo un coeficiente reductor de la edad en el art. 2.1 en los siguientes términos: "La edad mínima de sesenta y cinco años exigida para tener derecho a la pensión de jubilación se reducirá en un periodo equivalente al que resulte de aplicar al tiempo efectivamente trabajado en cada una de las categorías y especialidades profesionales que se indican el coeficiente que corresponda, de conformidad con la siguiente escala: a) El 0,40, en la de piloto y segundo piloto".

Es esta una norma que consiente la jubilación a una edad ordinaria inferior a la general establecida para el régimen general de la seguridad social, pero no implementa con carácter general la jubilación por cumplimiento de edad. Desde la reforma de 2003 no existe en nuestro ordenamiento jubilaciones obligatorias por razón de edad, lo cual abona la controversia en un tipo de actividad como la debatida tan singular desde el punto de vista de las facultades laborales que debe tener el trabajador. Con todo los algunos convenios colectivos del sector sí abordan la cuestión de la extinción por motivos de edad. 


\section{STJUE de 5 de diciembre de 2019 [C-398/18 y C-428/18] Bocero Torrico y Fritz Bode c. INSS y} TGSS. Pensión de jubilación anticipada y cuantía mínima

\section{A) Hechos del litigio principal}

67. La cuestión prejudicial ahora resuelta se ha planteado en un litigio en el que se discutía la concesión de una pensión de jubilación anticipada voluntaria.

Los señores Bocero y Fritz presentaron, por separado, una solicitud de jubilación anticipada en España. Ambos perciben al momento de la solicitud una pensión de jubilación del estado Alemán, en diferente cuantía.

Las dos solicitudes fueron rechazadas por el INSS con un mismo argumentos, que "su importe no alcanzaba el de la pensión mensual mínima que correspondería a los recurrente" al cumplir la edad de sesenta y cinco años de edad (§ 15), que es la exigencia que mantiene la norma de Seguridad Social interna.

Ambos trabajadores recurrieron, por separado, ante distintos juzgados, encontrando también idéntica respuesta negativa. La argumentación de ambas sentencia judiciales subrayaba que el art. 208.1.c) LGSS exige, efectivamente, que el importe de la referida pensión a percibir resulte "superior a la cuantía de la pensión mínima que correspondería al interesado por su situación familiar al cumplimiento de los sesenta y cinco años de edad".

Mismo supuesto de hecho, misma respuesta en vía administrativa y misma respuesta en vía jurisdiccional.

Los correspondientes recursos de suplicación fueron impetrados ante el mismo Tribunal Superior de Justicia, que es el que plantea la cuestión prejudicial comunitaria ahora resuelta por esta sentencia.

\section{B) Cuestión jurídica debatida}

68. La cuestión controvertida consiste en determinar si la exigencia normativa interna de que la pensión mínima de jubilación anticipada tenga que ser de cuantía superior a la mínima que le correspondería al alcanzar la edad de sesenta y cinco años es una exigencia referida únicamente en relación al ordenamiento jurídico español o si, por el contrario, el alcance de dicha cuantía mínima pueden alcanzarse con la cuantía sumada de las pensión que ya se percibe (del estado Alemán) junto con la que se percibiría por parte del ordenamiento Español (§ 18).

Lo cuestionado es si el concepto de "pensión a percibir" se integra únicamente con la cuantía de la pensión por jubilación anticipada que percibiría del ordenamiento Español, o si, por el contrario, para dicha cuantificación, debe también tenerse en consideración la que ya percibe del ordenamiento español (§ 28).

Es importante precisar que este cuestión prejudicial no se cuestiona la norma española que exige la referida cuantía mínima, que encuentra su justificación en desincentivar la utilización de este tipo de pensiones ( $(43)$. Se cuestiona, únicamente, si dicha cuantía puede integrarse por la suma de la que percibiría del ordenamiento español más la que ya percibe del sistema Alemán de protección de Seguridad Social. No se cuestiona, en definitiva, la norma, sino la interpretación que se hace de los requisitos en ella contenidos.

El Tribunal de Justicia entiende que para la cuantificación de la "pensión a percibir" debe tenerse en consideración "no solo el disfrute de las prestaciones de seguridad social adquiridas por el interesado en virtud de la legislación de ese Estado", sino también, y este es el punto esencial "el disfrute de las prestaciones equivalentes adquiridas en cualquier otro Estado miembro" (§35). Parte de la base de que las pensiones en ambos países son "equivalentes" en el sentido de que responden a la misma dinámica tuitiva (§ 37), y están pensadas para idénticos supuestos de hecho (§39), por lo que pueden complementarse.

Recuerda que el principio de igualdad de trato no sólo proscribe aquellas discriminaciones "ostensibles" basadas en la nacionalidad, sino también aquellas otras encubiertas ( $(40)$ que se apoyen o articulen en base a criterios de interpretación de las normas que provoque un peor trato a los trabajadores migrantes que aquel que se dispensaría a los de un país miembro (§ 41), por lo que aprecia que la 
negativa de las autoridades competentes españolas a tomar en consideración para el referido cómputo las pensiones que tiene un trabajador "que haya hecho uso de su derecho a la libre circulación tiene derecho en otro Estado miembro" sitúa "a dicho trabajador en una situación menos favorable que la de un trabajador que haya desarrollado toda su actividad profesional en el primer Estado miembro" ( $(42)$.

Porque, además, y este es el argumento que cierra el círculo de la apreciación de la discriminación, no se encuentran razones objetivas que sostengan la justificación de un tratamiento distintivo $(\S 43)$.

\section{C) Normativa UE en presencia}

69. Reglamento (CE) n. ${ }^{\circ} 883 / 2004$ del Parlamento Europeo y del Consejo, de 29 de abril de 2004, sobre la coordinación de los sistemas de seguridad social

\section{D) Resolución del Tribunal}

70. La normativa de la Unión referenciada sí se opone a una norma nacional que exige como requisito para acceder a una pensión de jubilación anticipada que su importe sea superior al de la pensión mínima que ese trabajador tendría derecho a percibir al cumplir la edad legal de jubilación.

\section{E) Apunte final}

71. La influencia de la jurisprudencia del Tribunal de Justicia sobre la pensión de jubilación española es tan evidente como preocupante. Evidente porque son ya numerosos los temas en los que se ha pronunciado, complemento de maternidad, pensión de trabajadores a tiempo parcial, etc. Preocupante porque revela que las últimas reformas, implementadas a la carrera con un propósito de sobrevivir a la debacle financiera del sistema, no han sido capaces de situar la más importante pensión en una senda de futuro. Quizá sea el momento de abordar una reforma legislativa que tenga en consideración más aspectos que los meramente financieros, sobre todo en esta evolución que experimenta el sistema desde los parámetros contributivos hacia los asistenciales.

\section{STJUE de 12 de diciembre de 2019 [C-450/18] WA c. INSS. El complemento de maternidad no debe excluir de su percibo a los varones que se encuentren en idéntica situación}

\section{A) Hechos del litigio principal}

72. La cuestión prejudicial se ha planteado en el contexto de un litigio entre WA, padre de dos hijos y el INSS en relación a la negativa de éste último en concederle el complemento económico a la pensión (que ya percibía) que el ordenamiento prevé exclusivamente para las mujeres que hayan sido madres de, al menos, de dos hijos, biológicos o adoptados.

El INSS concede a WA una pensión de incapacidad permanente absoluta, pero no atiende su reclamación con respecto al incremento de la misma (en un $5 \%$ ) que el ordenamiento prevé exclusivamente para mujeres que hayan sido madres de al menos dos hijos (§ 17).

Tras ver desestimada la reclamación administrativa $(\S 18)$ intima la correspondiente reclamación judicial (§ 19), produciéndose una sustitución procesal en la esposa del reclamante fallecido $(\S 20)$.

El Juzgado que debe resolver la pretensión expresa las dudas que le suscita un precepto (art. 60 LGSS) como el cuestionado que sólo consiente el complemento económico para las pensiones (en este caso de incapacidad permanente, pero también funciona operativamente para la pensión de jubilación) concedidas a las mujeres, excluyendo a los hombres que se encuentran en una situación jurídica idéntica $(\S 22)$. Comprende el propósito de la norma que regula el complemento, premiar la "aportación 
demográfica" a la Seguridad Social, pero aprecia que dicha aportación puede predicarse también de los hombres, en la medida en que contribuyen al cuidado y atención de la prole y pueden ver, por ello, sufrir "la interrupción del trabajo como consecuencia del nacimiento o adopción de los hijos o por el cuidado de los hijos" (\$22), aunque reconoce que la procreación "implica un mayor sacrificio para las mujeres a nivel personal y profesional' $(\S 23)$

El Tribunal expone los principios básicos que se deducen de la Directiva de igualdad de trato para afirmar, de forma categórica, que "resulta que esta norma nacional concede un trato menos favorable a los hombres que han tenido al menos dos hijos biológicos o adoptados", concluyendo que ese "trato menos favorable basado en el sexo puede constituir una discriminación directa" (§ 41), procedimiento a valorar si de las circunstancia concurrente en el caso puede afirmarse que se encuentra el recurrente en una situación comparable con la prevista abstractamente en la norma $(\S \S 42,43)$ no de una manera global, sino específica y concreta teniendo presente "el objeto y la finalidad de la normativa nacional que establezca la distinción" (§ 45).

Sobre este punto no tiene la menor duda alguna en afirmar con rotundidad que el objetivo perseguido por la norma, esto es, implementar una recompensa por la aportación demográfica "es tan necesaria [en los hombres] como la de las mujeres" (§ 46) de lo que infiere que no existe duda alguna de que tanto hombres como mujeres se encuentran en una situación comparable "en lo que respecta a la concesión del complemento de pensión controvertido" (§ 47).

El argumento que tumba definitivamente el complemento lo expresa con manifiesta claridad en el $\S 52$ cuando afirma, sin ambages, que "la circunstancia de que las mujeres estén más afectadas por las desventajas profesionales derivadas del cuidado de los hijos porque, en general, asumen esta tarea, no puede excluir la posibilidad de comparación de su situación con la de un hombre que asuma el cuidado de sus hijos y que, por esa razón, haya podido sufrir las mismas desventajas en su carrera".

No es, en definitiva, la circunstancia de ser hombre o mujer la determinante para el percibo del complemento, por lo que no supera el canon de legalidad comunitaria una norma como la enunciada que excluye a un varón del percibo del complemente cuando efectivamente se encuentra en idénticas circunstancias protegibles desde la perspectiva abstracta de la norma. Porque, concluye el Tribunal, la regla del art. 60 LGSS "no contiene ningún elemento que establezca un vínculo entre la concesión del complemento de pensión controvertido y el disfrute de un permiso de maternidad o las desventajas que sufre una mujer en su carrera debido a la interrupción de su actividad durante el periodo que sigue al parto" (§ 57), pues la norma no limitó el permiso a las situaciones de parto, ampliándolo también a los supuestos de adopción (§ 58).

El problema del art. 60 LGSS no es de filosofía política sino de implementación técnica. El Tribunal no niega que el objetivo pretendido por el precepto sea legítimo y tenga cabida dentro de las normas comunitarias. Niega, más concretamente, que tenga operatividad cuando excluye a los varones de su percibo. Por eso precisa, en el último $\S$ (el 60) antes del fallo que el precpeto cuestionado " $n o$ supedita la concesión del complemento de pensión en cuestión a la educación de los hijos o a la existencia de periodos de interrupción de empleo debidos a la educación de los hijos", sino "únicamente a que las mujeres beneficiarias hayan tenido al menos dos hijos biológicos o adoptados y perciban una pensión contributiva de jubilación, viudedad o incapacidad permanente en cualquier régimen del sistema de Seguridad Social'. No es, se insiste, el propósito legislativo el que ha quedado arrumbado, sino la mecánica técnica con la que se construye. Bien podía haber previsto la norma, por ejemplo, la situación protegible por el complemento, asegurándose que efectivamente el trabajador (generalmente mujer, aunque no siempre) ha perdido oportunidades laborales por cuidar de la prole.

\section{B) Cuestión jurídica debatida}

73. El Juzgado proponente pregunta si una ley nacional como la debatida que implementa el complemento económico para las pensiones únicamente para las mujeres que hayan tenido dos o más hijos por "aportación demográfica a la seguridad social" es contraria al ordenamiento jurídico al no concedérselo a los hombres que se encuentren en igualdad de condiciones. 


\section{C) Normativa UE en presencia}

74. Directiva 2006/54/CE del Parlamento Europeo y del Consejo, de 5 de julio de 2006, relativa a la aplicación del principio de igualdad de oportunidades e igualdad de trato entre hombres y mujeres en asuntos de empleo y ocupación.

Directiva 79/7/CEE del Consejo, de 19 de diciembre de 1978, relativa a la aplicación progresiva del principio de igualdad de trato entre hombres y mujeres en materia de seguridad social.

\section{D) Resolución del Tribunal}

75. La Directiva de igualdad de trato se opone a una norma como la debatida que, establece un complemento económico para las mujeres pensionistas de incapacidad permanente que hayan tenido al menos dos hijos y excluye a los hombres que se encuentren en idénticas situación.

\section{E) Apunte final}

76. La implementación del complemento de maternidad controvertido en esta resolución tiene más propósitos que los debatidos. Tiene un clara perspectiva de género, pues pretende, además de premiar la referida aportación demográfica a la seguridad social, desarrollar una política de género que consiga la igualación de las pensiones, especialmente la de jubilación, de las mujeres, pues tradicionalmente han tenida una mayor dedicación a la familia (no sólo a la prole) que ha lastrado su desarrollo profesional y laboral. El objetivo se reconocido por el Gobierno Español en sus alegaciones ( $§ 48)$, precisando que la norma también se implementa como un objetivo de política social (§ 49) con el propósito de reducir la brecha de género entre las pensiones de los hombres y las mujeres.

Desde este punto de vista el complemento parece justificarse en un propósito de la política de la Unión Europea, y quizá el argumentario del Gobierno Español podría haberse conducido por esta senda, manejando estadísticas que corroborasen la discriminación e incidiendo en esa perspectiva.

Dos problemas adicionales provoca el fallo del Tribunal de Justicia. El primero, relativamente sencillo de solventar, concretado en cuantificar el montante de la indemnización a los herederos del finado. El segundo, algo más complejo, abogaría por implementar una medida de política nacional que, sin lesionar los derechos a la igualdad de trato entre hombres y mujeres en la percepción de las pensiones de seguridad social, garantizase la medida (de acción positiva) de política social que jugaba el art. 60 LGSS. El legislador tiene la palabra. 